NBER WORKING PAPER SERIES

\title{
REFERENCE POINTS AND REDISTRIBUTIVE PREFERENCES: EXPERIMENTAL EVIDENCE
}

\author{
Jimmy Charité \\ Raymond Fisman \\ Ilyana Kuziemko
}

Working Paper 21009

http://www.nber.org/papers/w21009

\author{
NATIONAL BUREAU OF ECONOMIC RESEARCH \\ 1050 Massachusetts Avenue \\ Cambridge, MA 02138 \\ March 2015
}

We thank Alberto Alesina, Angus Deaton, Stefano DellaVigna, Marc Fleurbaey, Larry Katz, Benjamin Lockwood, David Moss, Howard Rudnick, Stefanie Stantcheva and Matt Weinzierl for helpful discussions, as well as seminar participants at the AEA meetings, Berkeley, Bocconi, UCSB, Chicago, Columbia, Harvard, LSE, NBER, Northwestern, Princeton, UPF, and Stockholm. Financial support from the Tobin Project is gratefully acknowledged. Adith Srinivasamurthy provided invaluable assistance with JavaScript programming. The views expressed herein are those of the authors and do not necessarily reflect the views of the National Bureau of Economic Research.

NBER working papers are circulated for discussion and comment purposes. They have not been peerreviewed or been subject to the review by the NBER Board of Directors that accompanies official NBER publications.

(C) 2015 by Jimmy Charité, Raymond Fisman, and Ilyana Kuziemko. All rights reserved. Short sections of text, not to exceed two paragraphs, may be quoted without explicit permission provided that full credit, including $\odot$ notice, is given to the source. 
Reference Points and Redistributive Preferences: Experimental Evidence Jimmy Charité, Raymond Fisman, and Ilyana Kuziemko

NBER Working Paper No. 21009

March 2015

JEL No. C9,D63,H21,H23

\begin{abstract}
$\underline{\text { ABSTRACT }}$
If individuals evaluate outcomes relative to the status quo, then a social planner may limit redistribution from rich to poor even in the absence of moral hazard. We present two experiments suggesting that individuals, placed in the position of a social planner, do in fact respect the reference points of others. First, subjects are given the opportunity to redistribute unequal, unearned initial endowments between two anonymous recipients. They redistribute significantly less when the recipients know the initial endowments (and thus may have formed corresponding reference points) than when the recipients do not know (when we observe near-complete redistribution). Subjects who are themselves risk-seeking over losses drive the effect, suggesting they project their own loss-aversion onto the recipients. In a separate experiment, respondents are asked to choose a tax rate for someone who (due to luck) became rich either five or one year(s) ago. Subjects faced with the five-year scenario choose a lower tax rate, indicating respect for the more deeply embedded (five-year) reference point. Our results thus suggest that respect for reference points of the wealthy may help explain why voters demand less redistribution than standard models predict.
\end{abstract}

Jimmy Charité

School of Business

Columbia University

8C Uris Hall

3022 Broadway

New York, NY 10027

jc4144@columbia.edu

Raymond Fisman

School of Business

Columbia University

622 Uris Hall

3022 Broadway

New York, NY 10027

and NBER

rf250@columbia.edu
Ilyana Kuziemko

Department of Economics

Princeton University

322 Wallace Hall

Princeton, NJ 08544

and NBER

kuziemko@princeton.edu 


\section{Introduction}

In a standard welfarist model of taxation with no moral hazard, a utilitarian social planner will aspire to equalize wealth across all members of society (Mirrlees, 1971). While moral hazard makes the social planner redistribute less, recent work suggests that standard estimates of labor supply elasticity yield higher marginal tax rates than are typically observed. ${ }^{1}$ Moving from the normative to the positive, a democratic political process would similarly be expected to generate a high degree of redistribution: given a right-skewed ex-ante income distribution, the majority of voters have an incentive to expropriate the rich (Meltzer and Richard, 1981).

However, many scholars have observed that neither survey-based expressions of policy preferences nor actual policies consistently reflect the more egalitarian predictions of standard models (see, e.g., Roemer, 1998 and citations therein). Perhaps the clearest challenge to the standard model is individuals' reluctance to fully redistribute exogenous, initial wealth, a contradiction to utilitarianism recently noted by Saez and Stantcheva (2013) and Weinzierl (2014). Scholars have proposed a number of explanations for the limited demand for redistribution. Past work has focused on the prospect of upward mobility (Benabou and Ok, 2001), the effects of "policy-bundling" redistribution with other, cross-cutting issues (typically race in the U.S. context, see Lee and Roemer, 2006), and the public's misinformation about income inequality (see Ariely and Norton, 2011 on the level of misinformation, though see also Kuziemko et al. (forthcoming) on the limited effect of information on policy preferences). ${ }^{2}$

This paper proposes an additional, heretofore unexplored explanation for the limited demand for redistribution, based on reference-dependent preferences. Whereas standard utility functions assume that only absolute levels of consumption enter into utility, decades of research support the view that in many important contexts individuals behave as though they evaluate options relative to a reference point, typically the status quo. In particular, individuals are loss-averse relative to this reference point, in that the reduction in utility from a (relative) loss is greater than the increase in utility from a corresponding gain. Further, to the extent that voters recognize the reference-dependence of others (and incorporate others' welfare into their own utility), they may demand limited redistribution from rich to poor, even with exogenous, unearned initial endowments.

\footnotetext{
${ }^{1}$ See Diamond and Saez (2011), who argue that a utilitarian social welfare function would yield top marginal tax rates over 70 percent given consensus estimates of labor supply elasticity.

${ }^{2}$ There is a related literature (see Harms and Zink, 2003 for a review) that examines why policy outcomes may be more regressive than voters' preferences even in a democracy (e.g., due to efforts by lobbying groups), but here we focus on the question of why voters' preferences might be more regressive than the predictions of standard models suggest they would be.
} 
We explore the consequences of reference dependence on the demand for redistribution in an experimental setting where endowments are random and exogenous, thus removing concerns of deservedness or efficiency, two key factors that could limit redistribution. Our subjects (referred to for convenience in the paper as "redistributors," though such language is never used in the experiments) were recruited via Amazon's Mechanical Turk (mTurk), a rapidly growing online labor market, which we describe in more detail later in the paper. The experiment confronts subjects with a redistributive decision involving two other (randomly selected and anonymous) mTurk participants, who received (based on a coin flip) initial endowments, with one assigned to receive 5 dollars and the other 15 . For most redistributors, the decision was presented as hypothetical; for a subset we confirmed that the results hold when subjects are informed that with 10 percent probability their decisions will be implemented for real stakes.

To vary redistributors' beliefs about the recipients' reference points, redistributors in the treatment arm were told that the recipients had already been informed of their ex-ante allocation; redistributors in the control arm were told that the recipients had not been informed of their ex-ante endowments and would thus only be informed of their ex-post allocation. Subjects were then free to redistribute (or not) any whole dollar amount between recipients, so long as all ex-post allocations remain non-negative. Each redistributor was presented with both treatment and control conditions, with the ordering chosen at random. For most of our analysis we use between-subject estimates of the loss aversion treatment based on subjects' responses to the first condition they are presented with.

Our main finding is that subjects in the reference-point treatment (where subjects are told that recipients have been informed of their ex-ante endowments) are significantly less likely to reduce inequality between recipients than subjects in the control condition. In our preferred specification, control group redistributors erase 94 percent of the initial 10 dollar difference between the recipients' endowments, while only 77 percent of endowment differences are removed through reallocation in the treatment group. Our estimates hold across a large number of robustness checks - dropping those who finish the survey in a suspiciously short amount of time, dropping those who choose to increase inequality, changing presentational aspects of the experiment, and moving from hypothetical to "real stakes" scenarios. Further, the estimates remained stable as we collected data on these variants over the course of nearly a year.

It bears repeating that we do not view our reference-point mechanism as supplanting other explanations for limited redistribution and take care to calibrate the size of our effect relative to what the literature suggests is one of the key barriers to redistribution: the sense 
that the well-off have earned (and hence deserve) their income. ${ }^{3}$ In one session, we asked respondents to redistribute unequal endowments between recipients whose initial allocations were assigned either by a coin toss, or earned by correctly answering Scholastic Assessment Test (SAT) questions, the main college admissions exam in the US. In both cases, the recipients would only know their final endowments, so the coin-toss scenario is identical to the control arm of the main experiment. Consistent with past work, we find strong effects of deservedness: in the SAT treatment, redistributors close $56 \%$ of the ex-ante gap. Our hypothesized "reference-dependence" mechanism thus has an effect size that is over half of the luck-versus-merit effect, suggesting it could be an important and heretofore overlooked explanation for limited redistribution.

There are several candidate explanations for the reference-dependent redistributive decisions of our subjects. Redistributors may (1) view initial allocations as property rights; (2) exhibit a status-quo bias; (3) believe that telling the recipients their initial endowments serves as an implicit promise, and thus reject redistribution on procedural justice grounds; (4) respect subjects' reference points. The near total redistribution in the control condition argues against the most straightforward versions of explanations based on property-rights or status-quo bias. To examine the potential role of procedural justice, we ran a version of the survey which informed subjects that recipients in the treatment condition had been told up front that their initial allocations could change before the receipt of payment. This phrasing should minimize procedural justice concerns, as redistributors can now reallocate money without worry of breaking an implicit promise to the treatment group recipients. Our results continue to hold in this variation, indicating that procedural justice is unlikely to be the primary explanation for our treatment effect.

Finally, we included a set of questions to measure redistributors' own loss aversion to assess whether individuals who themselves are more loss averse are less willing to redistribute in the treatment scenario. The vast majority of papers documenting loss-aversion use between-subject designs to establish the existence of loss-aversion. We need individuallevel measures in the intensity of loss-aversion to test whether this individual trait predicts differential treatment effects. We propose several such measures, each with its own shortcomings, which we discuss in greater detail in Section 3.2. We find that the treatment effect is driven almost entirely by subjects who are risk-loving in the loss domain: the interaction of this loss-aversion measure and treatment status is highly significant, and its inclusion drives the main treatment effect close to zero. We find no significant results for other loss-aversion proxies we employ. Overall, there is thus mixed evidence that individuals' own loss aversion predicts the magnitude of the treatment effect.

\footnotetext{
${ }^{3}$ See, for example, Alesina and Angeletos (2005) and Durante et al. (2013).
} 
Having established robust evidence that individuals respect recipients' reference points over small dollar amounts, we go on to examine whether reference points help explain voters' preferences over actual redistributive policies, using a survey experiment that elicits respondents' optimal tax rates on high-income individuals. Subjects were randomly assigned to one of two vignettes describing a person whose annual income had increased to $\$ 250,000$ owing to circumstances unrelated to skill or effort. The only difference between the treatment and control conditions was the length of time that the protagonist had been earning the higher income - in the treatment condition, he had been earning $\$ 250,000$ for five years and in the control condition for only one year. If respect for the reference points of the rich deters voters from demanding more redistribution, then the effect should be stronger in situations where that reference point has become more deeply embedded, i.e., for the individual who had already been earning $\$ 250,000$ for five years.

Consistent with this view, respondents chose a tax rate in the five-year scenario that is roughly 1.7 percentages points lower than in the one-year scenario (for which they chose a rate of 28 percent). This 1.7 percentage point difference is over half the size of the gap between tax rates chosen by Obama and Romney supporters, and is thus comparable in magnitude to other important predictors of tax preferences.

Our work joins a large body of economics papers that attempts to incorporate insights from social psychology. While earlier researchers have fruitfully modeled the implications of "behavioral agents" for the taxation of goods, to our knowledge, little work has adopted the optimal income tax framework to consider the consequences of non-standard preferences like reference-dependence on the demand for redistribution. ${ }^{4}$ This omission is surprising for at least two reasons. First, social preferences have played a central role in the field of behavioral economics and, in turn, social preferences are a central consideration in constructing a social welfare function and thus for determining optimal income taxation. Second, at least in the American context, income taxes account for a far greater fraction of revenue than do taxes on specific goods, and thus better understanding voters' preferences in this area has important, practical policy implications. ${ }^{5}$

Second, we contribute to a relatively recent literature on reconciling differences between

\footnotetext{
${ }^{4}$ See Bernheim and Rangel (2004) on optimal taxation when agents can become addicted to a good, O'Donoghue and Rabin (2006) on optimal "sin taxes" when agents lack self-control, and Allcott et al. (2014) on optimal energy taxes and subsidies when agents are inattentive. The work on optimal income tax is theoretical, not experimental, and focuses on relative utility - when utility is a function of consumptions levels of peers - and not on loss-aversion. See Boskin and Sheshinski (1978) and Oswald (1983).

${ }^{5}$ Alesina and Passarelli (2014) analyzes how loss aversion affects policy formulation in general. Their finding of a status quo bias is driven by the strength of preferences by losers versus winners, rather than voters' regard for the losses of others, as in our approach.
} 
individuals' stated policy preferences and the prescriptions from standard utilitarian optimal tax models. Both Saez and Stantcheva (2013) and Weinzierl (2014) point to individuals' reluctance to fully redistribute income even in the absence of moral hazard as a serious challenge to the utilitarian framework. We offer some evidence that the full-redistribution result can be largely rehabilitated within standard utilitarianism, albeit with non-standard individual utility functions. Both these papers note other important departures from utilitarianism (e.g., limited use of tagging) that we do not address in this paper.

Finally, to our knowledge, our study is one of the few to document choices that reflect the presumption of non-standard preferences on behalf of others. In this sense, our framework is related to models of guilt aversion (Battigalli and Dufwenberg, 2007), where individuals suffer disutility from a failure to meet the expectations of others, and as a result incorporate others' utility into their own choices (see Battigalli et al. (2013) and Ellingsen et al. (2010) for experimental tests of guilt aversion). Our results are novel in their application to important questions in public finance and their contribution to our understanding of redistributive preferences and policies.

The paper proceeds as follows. Section 2 presents a simple framework for thinking about optimal tax decisions with reference-dependent individuals. Section 3 describes the main lab experiment and Section 4 our mTurk sample. Section 5 reports the main results from the redistribution experiment. Section 6 introduces the tax-policy survey experiment and reports the results. Section 7 offers directions for future work and some concluding thoughts.

\section{Reference points and optimal taxation}

We begin by briefly examining how reference-dependent utility affects the prescriptions of a standard model of optimal taxation, focusing primarily on a single-period static case. We close with a discussion of how dynamics and possible adaptation would change the analysis. In our experiment we will not be explicitly testing this model; rather, it provides a framework for motivating and organizing our results based on existing theory.

\subsection{Redistribution in a static optimal tax model}

\subsubsection{With standard utility assumptions}

Even in the absence of moral hazard the standard optimal tax exercise would be intractable without assumptions on individual utility. As Mankiw et al. (2009) point out, despite the general caveat that utility cannot be compared across individuals, the typical optimal tax

exercise does exactly that and further assumes that individuals have identical utility func- 
tions: a function $f: x \rightarrow u$ maps consumption $x$ (which in the static model is identical to income or wealth) into utility $u$, with $f^{\prime}>0$ and $f^{\prime \prime}<0$.

With these assumptions, optimal taxation in the utilitarian framework with no moral hazard is a simple exercise. Assuming a single convex function can capture all agents' utility, welfare is maximized at the point of total equality.

Figure 1 illustrates this logic for two individuals $p$ (poor) and $r$ (rich), with ex-ante unequal wealth endowments $x_{p}$ and $x_{r}, x_{p}<x_{r}$. Given $r$ 's lower marginal utility of wealth, a social planner can increase total utility by transferring some $\Delta$ from $r$ to $p$. The social planner can continue to do so and still increase total welfare up to the point where $f^{\prime}\left(x_{r}\right)=f^{\prime}\left(x_{p}\right)$, that is, $x_{r}=x_{p}$.

\subsubsection{With reference-dependent utility}

If utility is reference-dependent, we lose the analytical convenience of both a common utility function across individuals as well as differentiability. Figure 2 shows typical referencedependent utility functions. ${ }^{6}$ Importantly, $r$ and $p$ no longer share a utility function, as each has a point of non-differentiability at their status-quo position. Transferring $\Delta x$ from $r$ to $p$ no longer guarantees welfare improvements. As shown in the figure, moving to complete equality is welfare-reducing, as is any smaller perturbation that transfers endowments from $r$ to $p$.

While we have drawn gains as concave and losses as convex in Figure 2, such restrictions are not necessary for the local result. So long as losses loom larger than gains relative to the reference point, then small amounts of redistribution will reduce welfare. It is harder to make specific claims about much larger changes, which will depend on third derivatives. The main point is that reference dependence weakens the claim that, without moral hazard, redistribution is necessarily welfare-enhancing in a utilitarian framework.

An alternative mechanism that delivers the same result is to assume that subjects have standard utility, but that the social planner himself overweights the utility of losers relative to winners, as in Saez and Stantcheva (2013). That is, loss-aversion enters via the social welfare weights, not the individuals' utility functions. Our experiments will not be able to distinguish between these two mechanisms.

\footnotetext{
${ }^{6}$ We draw the shape of the utility functions in Figure 2 to roughly approximate those calibrated in Abdellaoui et al. (2007).
} 


\subsection{Reference points in a dynamic setting}

The analysis in the previous subsection assumes a static setting where an individual forms a single reference point from her ex-ante endowment and then experiences a one-time change in utility based on the ex-post distribution. In reality, the government sets tax and transfer policy continuously. While a decision to substantially redistribute income or wealth in a given year might well have the utility consequences described above in the year that follows, if individuals adapt to their new reference points then the formerly rich will experience only momentary disutility in subsequent years.

It is an open question how quickly people adapt to changes in income and thus how malleable reference points are over time. ${ }^{7}$ Strictly speaking, our empirical work will sidestep this question: we merely test whether individuals appear to respect others' reference points when deciding whether to redistribute. Finding, as we do, that they respect others' reference points implies that individuals think that others' reference points are not completely malleable, or that they think myopically when making redistributive decisions. Thus, the actual adaptation of reference points is not relevant to the positive question of whether individuals, acting as social planners, believe others' reference points should enter into redistributive decisions.

However, while not the focus of our analysis here, adaptation is an important consideration in drawing normative implications from this positive result. If adaptation is slow and losses loom larger than gains, then voters who seek to limit redistribution are plausibly maximizing welfare in the utilitarian model. While past work (Chetty and Szeidl, 2007) has shown that reference points (in their case, built on the micro-foundation of consumption commitments) imply higher levels of social insurance against adverse events (as losses have greater utility cost with reference points than with standard utility), by the same logic reference points might also suggest lower levels of redistribution for the purpose of condensing the current income or wage distribution.

On the other hand, if adaptation is rapid, voters seeking to limit redistribution out of respect for others' references points might not be maximizing welfare, or at least not in a longer-run, steady-state sense. If voters or policy-makers overestimate the persistence of reference points, then their chosen level of redistribution may be lower than the optimal, welfare-maximizing point.

\footnotetext{
${ }^{7}$ See, e.g., Di Tella et al. (2010) and citations therein. They find that individual happiness measures return to baseline roughly four years after an income shock.
} 


\section{Experimental design}

We recruited and compensated our subjects through Amazon's Mechanical Turk (mTurk) marketplace (which we describe in detail in Section 4), but redirect them to surveys that we built with Qualtrics' online survey software, adding functionality with JavaScript as needed.

We collected data from ten distinct sessions. In seven of these, respondents proceeded through modules of the survey in the following order: (1) the main redistribution experiment; (2) questions on loss-aversion; (3) background questions on political beliefs and demographics. We describe each below. In three of the later surveys, subjects were presented first with questions on income taxation, which we describe in detail in Section 6. See Appendix Table 1 for the dates of the surveys and the attributes of each. ${ }^{8}$

\subsection{Main redistribution experiment}

The centerpiece of the survey presents respondents (whom we term "redistributors" in the paper, though at no time do we use this term in the survey itself) with the opportunity, in most cases hypothetical, to transfer money between two other anonymous mTurk participants. In all cases, the redistributor received only his show-up fee regardless of his decision, so he has no direct self-interested motivation.

Respondents randomized into the control arm of the survey encountered the following instructions:

Consider two other participants on mTurk, person A and person B. Based on a coin flip, we have given $\$ 5$ to person A and $\$ 15$ to person B.

You can now transfer money between persons A and B. Persons $A$ and $B$ are not told how much money they were initially given. If you decide to give Person A $\$ \mathrm{X}$ instead of $\$ 5$, he or she will simply be told that they have been given $\$ \mathrm{X}$, and will not know how much they started with. Nor will they know that there is another person (Person B) involved, or that a third party (you) determined the money they received.

Please indicate below what transfer, if any, you would make.

A slider and interactive bar graph (which reflects in real time movements of the slider) appeared directly below these instructions, allowing respondents to easily and transparently

${ }^{8}$ We had technical problems in one session and thus do not include it in the main analysis. A description of the problem as well as results from that session appear on the last page of the Appendix. 
transfer money between players. The default position of the slider was on the ex-ante $(\$ 5$, \$15) distribution. Appendix Figure 1 provides a screenshot.

For those randomized into the treatment arm, the second paragraph of the control instructions was modified as follows:

You can now transfer money between persons A and B. Persons $A$ and $B$ have already been told how much money we have given them. If you decide to give Person A $\$ \mathrm{X}$ instead of $\$ 5$, they will be told that they now have $\$ \mathrm{X}$ instead of \$5. They will not know that there is another person (Person B) involved, or that a third party (you) determined the money they received.

Appendix Figure 2 provides a screenshot.

To test the robustness of the results to within-person instead of between-person variation, we also performed the "reverse experiment" and so immediately after answering the treatment (control) version of the question, treatment (control) respondents answer the control (treatment) version of the question (with the labels "Persons A and B" replaced with "Persons C and D"). The survey is available for interested readers to take online. ${ }^{9}$

Two presentational aspects of the main experiment deserve mention. First, the use of the slider requires a default position, which we set to the status-quo allocation of $\$ 5$ and $\$ 15$ dollars. As such, we suspect that anchoring bias could lower the amount of redistribution in both treatment and control and thus attenuate any treatment effect. Second, to illustrate clearly the treatment scenario, we write: "If you decide to give Person A $\$$ X instead of $\$ 5$, they will be told that they now have $\$ \mathrm{X}$ instead of $\$ 5$." By using the poorer person as the illustration, if anything we should prime redistributors to think of the pleasant surprise that the person starting with $\$ 5$ will experience, again biasing the experiment against finding our hypothesized effect.

To ensure the robustness of our findings, we ran several variants on the main experiment described above. First, for one group of subjects (session 7), the subjects were informed, prior to seeing the instructions, that there was a ten percent chance their decision would be implemented for real stakes:

The next two questions will give you the opportunity to determine the payments to two other mTurk participants.

\footnotetext{
${ }^{9} \mathrm{~A}$ version of the online experiment where the redistribution experiment is presented first can be taken at the following link: https://az1. qualtrics.com/SE/?SID=SV_b2Tk5a7LuYAk38F\& Preview=Survey\&BrandID=columbia. A version of the online experiment where the tax experiment is presented first can be taken at this link: https://az1.qualtrics.com/SE/?SID=SV_ OMnchCiPWRxAsqV\&Preview=Survey\&BrandID=columbia. These versions of the surveys are in "preview" mode and thus we do not collect any identifying data - such as IP addresses - via these links.
} 
After you make your decisions, the computer will pick at random whether or not to implement your decision. There is a $10 \%$ percent chance that one of your decisions will actually be implemented. Because you do not know ahead of time whether your decision will be chosen, you should make your decisions as if they were for real money.

In another robustness check (session 8), none of the text was italicized or underlined, and the underlined reminder message (see screenshots in the Appendix) placed next to the slider was removed. In a final check (session 10), we altered the language in the treatment condition to convey to redistributors that the initial endowments should not be seen as a promise or obligation to persons A or B. As Leventhal (1980) notes, the procedural justice "rule of adhering to commitments...dictates that fairness is violated unless persons receive that which has been promised to them." To limit redistributors' sense of commitment to an initially promised allocation, we modified the wording of the underlined portion of the instructions to read: "Persons A and B were told how much money they were initially given, though they have also been told that the amount might increase or decrease." All other text was unchanged.

\subsection{Questions to determine respondents' own sensitivity to refer- ence points}

We will also examine the role of redistributors' own loss aversion on the treatment effect. In the theory presented in Section 2 the social planner incorporates individuals' loss aversion in calculating social welfare; we conjecture that this tendency may be greater amongst subjects who are themselves more sensitive to reference points. Such individuals will therefore exhibit a larger treatment effect, as they project their own loss-aversion onto recipients' outcomes.

This test requires an individual-level measure of loss-aversion. However, the vast majority of papers on loss-aversion use between-subject analysis - for example, the classic endowmenteffect experiments are demonstrated by one group's willingness to accept being higher than another group's willingness to pay which, by construction, is a between-subject exercise. Similarly, in their work showing that respondents judge the fairness of market transactions based on reference points, Kahneman et al. (1986) use comparisons between groups assigned to read different vignettes.

Our approach is largely to take the questions asked in between-subject designs and present both versions to each subject. Our primary measure of loss aversion, adapted from Kahneman and Tversky (1979), uses the following sets of questions to measure risk-attitudes over gains relative to losses. 
Imagine that you face the following decisions. For each decision, please examine both options and indicate the one that you prefer.

- Decision One:

- A sure gain of $\$ 5$.

- $50 \%$ chance to gain $\$ 8$ and $50 \%$ chance to gain nothing.

- Decision Two:

- A sure gain of $\$ 5$.

- $50 \%$ chance to gain $\$ 11$ and $50 \%$ chance to gain nothing.

- Decision Three:

- A sure gain of $\$ 5$.

- $50 \%$ chance to gain $\$ 14$ and $50 \%$ chance to gain nothing.

Subjects then faced the same gambles, but in the loss domain:

- Decision One:

- A sure loss of $\$ 5$.

- $50 \%$ chance to lose $\$ 8$ and $50 \%$ chance to lose nothing.

- Decision Two:

- A sure loss of $\$ 5$.

- $50 \%$ chance to lose $\$ 11$ and $50 \%$ chance to lose nothing.

- Decision Three:

- A sure loss of $\$ 5$.

- $50 \%$ chance to lose $\$ 14$ and $50 \%$ chance to lose nothing.

We supplement this approach with additional questions on behaviors that prior researchers have suggested relate to loss aversion. The first is motivated by the empirical results documented in Genesove and Mayer (2001) showing that sellers of owner-occupied homes eschew offers below the price at which they bought their own house to avoid realizing a loss:

Suppose you bought a house for $\$ 250,000$ a few years ago. The housing market in your neighborhood has since declined, and you have seen houses very similar to yours sell for $\$ 200,000$, though some sell for a bit more and some sell for a bit less. You expect the current housing market conditions in your neighborhood to remain relatively stable. You are planning to relocate in the coming year for a new job. Someone is interested in buying your house. What is the least you would be willing to accept as a sale price? 
Subjects were then confronted with a question that was identical, except that the house's purchase price was changed from $\$ 250,000$ to $\$ 300,000$.

Second, we take a question from Kahneman et al. (1986) that relates to referencedependent preferences over an employee's wages:

A small coffee shop has one employee who has worked there for six months and earns $\$ 10$ per hour. The shop continues to do fairly good business, though unemployment in the area has increased due to a factory closure nearby. As a result, other small restaurants have now hired reliable workers at $\$ 8$ an hour to perform jobs similar to those done by the coffee shop employee. The owner of the coffee shop reduces the employee's wage to $\$ 8$. The owner's actions were: $\circ$ Completely fair o Acceptable o Unfair o Very unfair.

Subjects were then presented with a version of the question where the penultimate sentence is changed to: "The current employee leaves, and the owner decides to pay a replacement worker $\$ 8$ an hour."

Appendix Table 2 shows the correlation among these measures. Intriguingly, the answers to the vignettes appear largely uncorrelated with the classic measure of being risk-loving over losses, suggesting that they are capturing distinct phenomena. We return to the limitations of these proxies later in the paper.

\subsection{Demographic and political opinion questions}

The survey ended with standard demographic questions, as well as a question of affiliation in the 2012 presidential election. These questions allow us to examine whether our treatment effect is larger for certain groups, and also to compare the mTurk sample to more representative populations such as the American Community Survey. Given that we collect these questions after the experiment (so as not to prime the results in the experiment), it is possible that some answers may be primed by the experiment itself; comparisons by these covariates should thus be viewed with this potential priming in mind. The final questions of the survey relate to whether respondents felt any part of the survey was confusing or biased and also asked for any other feedback they wished to share. 


\section{Data}

\subsection{Data collection procedures}

All of our subjects were recruited through mTurk, an online labor market where "requesters" can post human intelligence tasks (HITs) to be completed by "workers." As of this writing, mTurk advertises that requesters can "access more than 500,000 workers." The most common posted HIT currently is "extract purchased items from a shopping receipt" and pays 8 cents (the requester also pays a ten percent commission to Amazon). ${ }^{10}$

Over the past few years, social scientists have increasingly used mTurk to perform experiments and collect survey data (see Kuziemko et al., forthcoming and papers cited therein for a review). We registered as a requester and posted the following HIT: "Short (less than ten minutes) opinion survey on a variety of topics." We tried to use a neutral description that would limit selection bias while also giving workers an honest description of the task. Compensation was set to $\$ 1$, which approximated minimum wage assuming that subjects took seven or eight minutes to complete it. Actual median completion time was 10.1 minutes, implying an hourly wage of $\$ 6.09$. Though we cannot find official data on average wages on mTurk, reading through worker forums suggests that we are paying a very generous wage (and indeed when we post a request for 300 survey takers, the full sample is typically gathered within an hour).

Each worker logs in with an mTurk worker ID. We collected data over ten separate sessions, dropping any worker who has taken a previous survey with the same ID so as to gather a fresh sample each time (though our main results hold when we keep repeat-takers in the sample, see Appendix Table 6). Of course, if workers have multiple worker IDs then some individuals may have participated in a previous session. Outside of surveys (which appear to make up a very small share of all HITs), in which case requesters may want unique workers, there is little financial incentive for mTurk workers to create multiple mTurk IDs, but we cannot completely eliminate the possibility that some have done so, and thus could have passed through our screening process.

Another issue that arises on mTurk is the possibility of 'robots,' algorithms that masquerade as humans. To address this concern we begin each survey with a "captcha" (nonstandard writing difficult for computers to interpret). ${ }^{11}$ To the extent some robots remain in our sample, they would attenuate any treatment effect.

\footnotetext{
${ }^{10}$ Details cited in this paragraph are based on viewing the mTurk homepage on 10:56 AM EDT, August 12, 2014.

${ }^{11}$ Examples of "captchas" can be found here: http://www.fileflash.com/graphics/screens/ Captcha_Creator_PHP_Script-69.gif.
} 
To limit heterogeneity of the sample, we collect all data on workdays during daylight hours on the East Coast of the United States. Individuals were automatically prompted for a response when they tried to skip questions (to discourage robots or inattentive respondents). Particularly given our focus in some parts of the survey on American tax policy, we limited the survey's availability to those with U.S. billing addresses; we further asked respondents to confirm their residency in the United States. To further ensure the attentiveness of our subjects, we limit respondents to those with positive ratings from at least 90 percent of past requesters.

The data pass basic reality checks (for example, subjects that report having supported Mitt Romney in 2012 tend to be white and male, mirroring patterns observed in polling data). Over three quarters of respondents went on to answer an open-ended "feedback" question, with the vast majority providing positive feedback on the survey. ${ }^{12}$

In Appendix Tables 3 we show how questions on perceived political bias of the survey vary with treatment status. About 87 percent of respondents felt that the survey was unbiased, with about 9 percent finding that it had a liberal slant and 3 percent a conservative slant. There is a borderline significant difference in perceived bias among treatment and control subjects (column 3), though the bias is split between those that say the experiment was leftand right-wing biased (columns 1 and 2), and neither directional bias is significant. Similarly, survey fatigue should not affect our estimates of the treatment effect, as the average number of minutes taken to complete the survey is also independent of treatment status.

\subsection{Data sample}

Table 1 provides detail on the mTurk workers who completed our survey, comparing them to the (weighted) population of adults sampled in the 2010 American Community Survey. Consistent with past work using mTurk, we find that younger, male, and college-educated subjects are over-represented in our sample, while minorities are under-represented.

Table 2 provides a longer list of covariates, while Table 3 examines differences between the control and treatment groups. Overall, there appears to be good experimental balance, with no variable showing a statistically significant difference at the five-percent level. In particular, a variable that would be expected to have an impact on redistributive decisions - an indicator for supporting President Obama in the 2012 election - is essentially identical between the treatment and controls groups ( $p$ value of 0.89 ).

Our loss-aversion measures also appear relatively balanced across survey arms. $R$-loving

\footnotetext{
${ }^{12}$ The positive feedback likely reflects the tedium of most other mTurk tasks. Essentially all of the negative feedback concerned the difficulty of some of the "captchas," suggesting that it would be difficult for robots to pass through this screen.
} 
in losses is coded as 0 if the respondent rejects all three gambles in the loss domain, 1 if she accepts only the $\$ 8$ gamble, 2 if both the $\$ 8$ and $\$ 11$, and 3 if she accepts all three gambles. $R$-loving in gains is defined in a parallel manner. Our respondents are more risk-loving in losses than gains, but there are no differences across survey arms. $L$ - $G$ risk subtracts $R$ loving in gains from $R$-loving in losses as an additional loss-aversion measure: in this case, how much more risk-loving a respondent is in losses than in gains.

The last two variables refer to our loss-aversion vignettes. Higher WTA indicates that the respondent demanded a higher house price with a $\$ 300,000$ initial price than the $\$ 250,000$ price. $80 \%$ of our respondents felt that the initial price was relevant to their decision. Finally, $\Delta$ wage unfairness takes the 1-4 rating of unfairness that the employer would cut the current employee's wage to $\$ 8$, and subtracts the same rating for the new employee. It is thus a measure of how much more unfair the cut is to the current employee and, indeed, our respondents view it as substantially more unfair. Thus, for both measures the reference point effect survives a within-subject comparison, despite subjects seeing the scenarios side by side.

\section{$5 \quad$ Results from the redistribution experiment}

\subsection{Main results}

Table 4 shows, for the full sample, the main between-subject differences in total redistribution for those first assigned to the control versus those first assigned to the treatment. Recall that redistributing $\$ 5$ from the "richer" to "poorer" recipient would result in complete redistribution. Column (1) shows the treatment effect controlling only for session fixed effects. Those in the control group achieve nearly complete redistribution, shifting an average of $\$ 4.55$ from the richer recipient to the poorer one, or $91 \%$ of the level of redistribution required for strict equality. Recall that the default position of the slider was the status quo ( $\$ 5$ and \$15) allocations, suggesting that anchoring may, if anything, bias the control group results against inequality-reducing redistribution. Those assigned to the treatment redistribute on average $\$ 0.80$ (or 17 percent) less than those in the control.

Column (2) drops subjects who finished the survey in less time than one could reasonably be capable of completing it. ${ }^{13}$ The control group mean increases slightly, consistent with the view that some rapid finishers simply clicked thoughtlessly through the redistributive decisions, leaving the sliders in their default positions. The treatment effect increases when

\footnotetext{
${ }^{13}$ Specifically, less than three minutes for the first session (as it did not have the module on loss-aversion), and six minutes for the other sessions.
} 
these subjects are dropped.

Column (3) further excludes subjects for whom the $\$ 5 / \$ 15$ experiment was not the first item of the survey. This restriction removes subjects that may be contaminated by exposure to our income tax survey experiment (which we discuss in Section 6 below). We take the results in this column as our preferred specification: the control group closes nearly $94 \%$ of the gap $(4.682 \div 5)$, whereas the treatment group only $77((4.683-0.829) \div 5)$. Thus, our treatment reduces redistribution by 17 percentage points.

The rest of the table provides a number of additional robustness checks. In column (4) we drop subjects who choose to make inequality-increasing reallocations. We present results with these subjects excluded to ensure that our average treatment effect is not being driven by them (though one could imagine such choices as welfare-maximizing under, say, a convex utility function). Column (5) includes a number of demographic control variables; given the balance across the control and treatment arms documented in Table 3, it is not surprising that the treatment effect is unchanged with the inclusion of these controls. Column (6) presents results for the "real stakes" subsample of redistributors who were informed that there was a 10 percent chance that their decision would be implemented, while in Column (7), we show results for the group of subjects where none of the text in the experiment was highlighted or underlined. We find that our basic result continues to hold in each of these subsamples, though the effect is attenuated, particularly in the non-underlined version.

Finally, in column (8) we present the results of the variant designed to assess whether procedural justice concerns can account for our treatment effect, labeled "Ex. promised payment" in the table. Recall that in this version, subjects in the treatment group were informed that "Persons A and B were told how much money they were initially given, though they have also been told that the amount might increase or decrease." While the treatment effect is marginally smaller than that observed in our main results $(-0.51$ versus -0.83$)$, it is still significant at the $10 \%$ level. This check is quite demanding: by warning (hypothetical) subjects in the treatment condition that their ex-ante allocation could change, we are not only avoiding making a promise but also softening their reference points. As such, even if procedural justice issues played no role in the main treatment effect, we might expect the treatment effect in this session to be somewhat smaller if redistributors are instead responding to the softened reference point of the hypothetical subjects.

Our main results are consistent across sessions more generally, as shown in Figure 3. Here, using our preferred sample restrictions, we plot the coefficients and 95 percent confidence intervals for the treatment effect, disaggregated by session date. The only treatment effect that stands out is the very first survey, which is larger in magnitude than the others. While, as noted, we drop individuals who participated in previous sessions with the same mTurk ID, 
the large treatment effect for the first survey potentially suggests that individuals who already took the survey using a different worker ID may have attenuated the measured treatment effect in later sessions. The session-by-session results highlight how the "real stakes" and "unemphasized" versions of the survey have nearly identical treatment effects as the two standard surveys that followed the initial session.

Figure 4 shows histograms of the final allocation for the ex-ante "poorer" player, both for the treatment and control groups. For both groups, the distribution is bimodal, with most of the mass at $(10,10)$ but also a second, shorter peak at $(5,15)$; there is almost no mass in between these two points. Thus, most of the treatment effect occurs at the extensive margin - the decision to redistribute at all - as opposed to increases in partial redistribution. If losses are "more convex" than gains are "concave," then after no redistribution, complete redistribution is the utility-maximizing outcome. As such, the lack of partial redistribution is consistent with subjects responding to the convexity of losses.

Table 5 shows these extensive margin results in a regression framework. Approximately four-fifths of control group respondents set final allocations at $(10,10)$, as compared to only 60 percent of the treatment group, for a treatment effect of 25 percent along the extensive margin. As before, this result is highly robust to the addition of controls, as well as excluding suspiciously short surveys, and choices that increase inequality.

As noted in Section 3, all subjects are presented with the "reverse" experiment: those first assigned to the treatment also face the control scenario, and vice versa. Our emphasis is on the between-subjects analysis presented above, as respondents are likely to anchor at least partially on their first response, and past work has further shown that the tendency to anchor may be related to loss-aversion. ${ }^{14}$ Nonetheless, the within-subject treatment effect is highly significant, and near-identical in magnitude to the between-subject estimates. Table 6 shows an average treatment effect of -0.873 (column 1), with a somewhat smaller effect (column 2) for those who start with the treatment scenario than those who start with the control scenario (column 3). The final column shows that the within-subject result holds also for the real-stakes session.

\subsection{Magnitude of the reference point effect}

To gauge the magnitude of the effect we document above, we compare our treatment effect to the impact of having endowments earned by merit (score on SAT questions) rather than luck (a coin flip). This comparison is motivated by prior work using polling data, which has shown that one of the most important determinants of support for redistribution is whether

\footnotetext{
${ }^{14}$ See Beggs and Graddy (2009).
} 
income is seen as the result of merit versus luck (Alesina and Angeletos, 2005).

To make this comparison, we ran a session where the control arm was kept the same (the $\$ 5$ and $\$ 15$ endowments were determined by a coin flip, and the recipients will only know their final allocations), while in the treatment arm respondents were told "the initial amounts given to Persons A and B were based on their performance on SAT questions [emph. in original]." As with the control version of the experiment, the redistributor is told that Persons A and B would only learn of their own final allocation.

The results are reported in Table 7 . Consistent with past work demonstrating the important role of perceived merit in attitudes toward redistribution, the coefficient on the treatment variable is large in magnitude, indeed larger than in our reference-point experiment. Dividing the coefficients in this table by their analogues in Table 4 suggests that our reference-point effect is about half of the luck-versus-merit difference. ${ }^{15}$ It is possible that the SAT treatment contains an implicit reference point treatment as well: a subject would likely have a rough sense of their performance, and thus form a reference point over their expected compensation. To the extent that redistributors take this expectation into account, we would over-estimate the pure "merit" effect (thus underestimating the magnitude of our main reference-point treatment effect as a share of the merit effect).

Interestingly, the histogram of final outcomes in the luck-merit experiment takes a somewhat different shape than what we observe for the main experiment (see Appendix Figure 5). There are still mass points at $\$ 5$ and $\$ 10$, but other intermediate choices are now more common. Whereas, conditional on redistributing something, only 12 percent of those assigned to the original treatment chose an "in between" final allocation in the reference-point experiment, 28 percent do so in the luck-versus-merit experiment, highlighting that respondents are more sensitive to the assigned reference points in our main loss aversion treatment.

\subsection{Why do redistributors exhibit reference dependence?}

There are several primary candidate explanations for the treatment effect we observe: property rights over initial endowments, status-quo bias, initial endowments as a commitment or promise, and the projection of loss-averse preferences on recipients by the redistributors. The data are harder to reconcile with either of the first two explanations. The most straightforward property rights explanation is inconsistent with the near-complete redistribution in our control condition. This result also casts doubt on status-quo bias, which would also limit

\footnotetext{
${ }^{15}$ Our luck-versus-merit results are similar to those found in preliminary work by Chevanne et al. In an undated online draft of their paper, they find that third-party dictators redistribute roughly 32 percent less when they are told that initial inequality was due to effort, quite close to the effect we obtain in our experiment (a 36 percent reduction in the specification with controls).
} 
redistribution in the control scenario.

Of course, applying the notion of "property rights" is complicated in our control condition: can one have "property rights" over something one was unaware that one possessed? In the "no promises" variant of the experiment, however, "property rights" in the treatment condition are deliberately weakened by warning the recipients that their ex-ante allocations could change. Yet the treatment effect remains, suggesting a respect for property rights are not the main constraint on redistributors in the treatment condition. Moreover, this "no promises" variant also argues against a dominant role of distributive obligations as a result of commitments or promises.

In the remainder of this section, we assess the evidence for the final candidate explanationthat the redistributor projects reference-dependent preferences onto the potential recipients A and B. We hypothesize that this is more likely if a redistributor is himself more loss-averse. We thus examine how the treatment effect varies with measures of own loss aversion in Table 8 , using regressions of the form

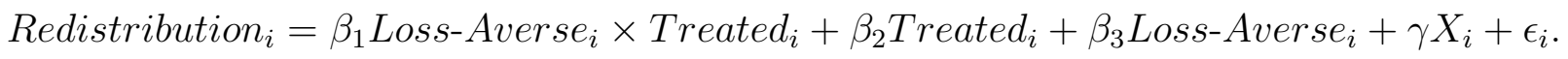

We conjecture that $\beta_{1}<0$; that is, those who are loss-averse will redistribute relatively less than others when exposed to the treatment condition. ${ }^{16}$

Table 8 shows mixed support for the notion that the treatment is strongest among lossaverse subjects. In column (1) we replicate our preferred specification from the main experiment, for ease of comparison. In column (2) we add the interaction between treatment status and our measure of risk-seeking over losses (along with its main effect, though we do not report this coefficient in the interest of space). ${ }^{17}$ The coefficient on the interaction term is negative and highly significant; moreover, it reduces the main effect of the treatment essentially to zero. Column (3) shows that risk attitude over gains has no significant effect on the treatment. When we subtract risk attitude in gains from risk attitude in losses (to compare risk-taking over losses relative to risk-taking over gains) we also find a significant interaction effect in the expected direction (column 4).

However, when we turn to our alternative loss aversion measures, neither interaction term approaches statistical significance (and in fact both point estimates go against the

\footnotetext{
${ }^{16}$ This regression presents a demanding test: as Table 2 shows, a large majority of individuals give answers consistent with loss aversion in the surveys. Given that the main treatment effect acts primarily through the extensive margin, it is plausible that individuals with varying degrees of loss aversion over own payoffs will have similar treatment effects, so long as they are above some threshold level of loss-aversion.

${ }^{17}$ Main effects of each of the reference-dependence proxies are all small and statistically insignificant; the coefficients flip signs depending on which proxy is used.
} 
hypothesized direction). As we note earlier, none of our three main loss aversion measures show strong correlation with one another, raising the larger concern of how best to measure loss aversion in a simple and comprehensible way at the individual-level, a question we intend to take up in future research. It is also worth noting that the non-gamble loss-aversion measures have limited variation (e.g, roughly 80 percent of subjects say they would be unwilling to realize a loss when selling their house), so our ability to compare treatment effects by these measures are limited. Finally, because we always ask the loss-aversion questions after the main $\$ 5 / \$ 15$ experiment, priming from the main experiment (as well as priming among the loss-aversion questions) is likely. For the remainder of the subsection we focus on the gamble-based measures of loss-aversion.

Returning to our result in column (2), the strong effect of the interaction term could merely reflect a differential treatment effect along another margin that correlates with lossaversion. In Appendix Table 4 we show results for our main covariates interacted with the treatment effect. Rather remarkably, of the eleven variables, only one (age) is even marginally significant. As such, differential treatment effects appear very small (outside of risk-preferences in the loss domain). Indeed, the Risk-loving in losses $\times$ Treatment effect in column (2) remains large and significant when in column (7) we simultaneously control for all the interactions documented in Appendix Table 4 (along with all underlying main effects), consistent with these additional controls having very little explanatory power. Column (8) shows that including all the Covariate $\times$ Treatment interactions does not affect the coefficient on interaction with risk-aversion over losses relative to risk-aversion over gains.

While the results in Table 8 indicate that our main results are driven by subjects who are risk-loving in the loss domain, it may be that these individuals are simply more sensitive to treatment effects more generally. To test this claim, in Appendix Table 5 we replicate the analysis in Table 8, using data from the SAT/coin-toss version of the experiment. While the sample size is small and our estimates correspondingly noisier, the pattern of coefficients offers no hint that being risk-loving over losses affects the treatment effect in the luck/merit experiment. The coefficient on the treatment's main effect is virtually unchanged when the interaction term is added, in sharp contrast to the patterns observed in Table 8.

\subsection{Discussion}

We find very robust evidence that in their role as social planner, subjects' decisions are affected by whether recipients are aware of their initial endowments. While subjects appear to respect the reference points of the potential recipients, we provide only tentative evidence that they project their own reference-dependence onto recipients, as the relationship of the 
treatment effect with own loss aversion is sensitive to the exact loss-aversion proxy used.

These experimental results suggest that respect for reference points may be one reason individuals eschew complete redistribution even in the absence of moral hazard. When redistributors need not consider recipients reference points, as in our control condition, we essentially recover the Mirrleesian full-redistribution result, making the results from the control arm interesting in their own right. We can thus rehabilitate the full-redistribution result within classic utilitarianism, albeit with non-standard utility functions.

As noted earlier, Chetty and Szeidl (2007) present a model of consumption commitments that could similarly diminish redistribution by a social planner who takes into account the commitments of relatively well-off individuals. As they observe, however, in a context such as ours it is implausible that actual consumption commitments could drive subjects' decisions - the individuals over whom they were making decisions were given money that, by construction, had not yet been spent. ${ }^{18}$

Our findings to this point indicate that subjects are sensitive to others' reference points in redistributive decisions in laboratory settings over small stakes. In order to relate our findings more directly to policy-relevant questions, we now turn to results from a survey experiment on preferences over income tax rates.

\section{Survey results on reference points and preferred top income tax rates}

The question of what constitutes an appropriate income tax rate on high-income households is a much-discussed issue in American politics today. A threshold of $\$ 250,000$ has become a focal point in this discussion, and surveys often ask about support for higher taxes on households with annual incomes of at least that level. ${ }^{19}$ While the majority of respondents in surveys tend to support higher income taxes on this group, the strength of those preferences has been debated. For example, while survey respondents in 2010 exhibited strong support for letting the so-called "Bush tax cuts" (those specified in the 2001 and 2003 tax relief acts) expire for individuals earning over $\$ 250,000$, in that year's midterm Congressional elections Republicans won handily despite their having made extending these tax cuts a major focus

\footnotetext{
${ }^{18}$ If individuals develop reference-dependent heuristics as a result of commonly observing consumption commitments in their day-to-day lives, it could help to provide an underlying model for reference dependent preferences. Examining this possibility may be an interesting direction to pursue but is outside the scope of our paper.

${ }^{19}$ See, e.g., http://politicalticker.blogs.cnn.com/2012/12/06/trio-of-polls-supportfor-raising-taxes-on-wealthy/.
} 
of their campaign. ${ }^{20}$

The survey experiment below tests whether respect for reference points might weaken respondents' preference to tax high-income households.

\subsection{The survey experiment}

Subjects were presented with a vignette describing an individual that had received an unexpected increase in earnings. In most waves, the source of the increase was a corporate takeover of the company where the individual is employed (the "takeover" vignette). Subjects were randomly assigned to either a treatment or control arm, which differed only in the timing of when the earnings increase took place.

The "control" arm of the vignette took the following form: ${ }^{21}$

There has been much talk about whether wealthy families are paying their fair share in taxes.

Consider the following person. He has been working for about five years as a regional sales manager at a medium-sized firm. This year, his firm was taken over by a larger corporation. While he will be doing the same job as before, to make his pay compatible with the earnings of employees in his position at the larger firm, his salary is now doubled, to $\$ 250,000$.

If it were up to you, how much of his salary should he pay in taxes? (As a basis of comparison, the average American pays about 22 percent in taxes on the income they make.)

In the treatment variant, we attempt to make the protagonists' reference income of $\$ 250,000$ more deeply embedded. Instead of receiving the raise just this year, he received it five years ago. Specifically, the second paragraph in the treatment vignette reads:

Consider the following person. He started five years ago as a regional sales manager at a medium-sized firm. Soon after starting, his firm was taken over by a larger corporation. While he did the same job as before, his salary was doubled to make his pay compatible with the earnings of employees in his position at the

\footnotetext{
${ }^{20}$ Larry Bartels discussed this tension in a 2010 online post: http://today.yougov.com/news/ 2010/10/26/taxes-energized-minority/.

${ }^{21}$ In the vignettes we reference a tax rate of 22 percent on the "average American." We base this figure on NBER Taxsim estimates for combined federal and state income tax, and then add the employee side of payroll taxes.
} 
larger firm. Since then, his annual salary has been roughly steady and is now $\$ 250,000$.

After reading either the control or treatment version of the vignette, subjects provided their response using a slider positioned immediately below the vignette, with values in the range $[0,100]$ percent and the default set to zero. See Appendix Figures 3 and 4 for screen shots.

In a later session, to assess the generalizability of our findings, we changed the reason for the individual's increase in income. In the control version of this later wave, the second paragraph of the vignette above is replaced with:

Consider the following person. This year, he won the state lottery. As a result, he will receive $\$ 250,000$ a year for the rest of his life (note that lottery winnings are treated as taxable income).

As before, in the treatment version, to strengthen the reference point, we simply replaced "This year" with "Five years ago" and changed the verb tense (from "will receive" to "receives") as appropriate.

In a subset of sessions, following the vignette and the associated slider question, we asked subjects about their tax preferences more generally as follows: "In general, how do you feel about increasing taxes on those making $\$ 250,000$ or more (as has been proposed in Congress recently)?" Respondents could choose from "strongly oppose," "oppose," "favor," and "strongly favor" (though we collapse these choices into an indicator variable for favoring or strongly favoring the policy).

Our analysis in this section is motivated by models of habit formation whereby individuals acclimate to conditions - financial or otherwise - over time (see, for example, Bowman et al. (1999)). Thus, we conjecture that subjects presented with a vignette where the protagonist has been receiving $\$ 250,000$ for nearly five years will set a lower ideal tax rate than those presented with a protagonist that has received high earnings for only a short time, and hence is not yet accustomed to it.

\subsection{Results}

We begin by presenting results based on the pooled sample of both takeover and lottery vignettes. In the first column of Table 9, we present the basic treatment effect, where Treated denotes that a subject was presented with the vignette where the protagonist's earnings (via corporate acquisition or lottery) increased five years ago, using the full sample of mTurk participants (even those that did not see the tax survey experiment first). Treated subjects 
choose a tax rate for the protagonist that is 1.17 percentage points lower than control subjects, significant at the 10 percent level; by comparison, the control group mean is 28.8 percent. As with the $\$ 5 / \$ 15$ experiment, our preferred sample includes only those who saw the tax experiment first (and thus cannot be contaminated with the $\$ 5 / \$ 15$ redistribution experiment). When we focus on the subsample where the tax vignette appeared first (column 2 ), the treatment effect increases to 1.71 percentage points (with a control group mean of 28.6).

A small fraction of subjects choose extreme values: about one percent of subjects selected a tax rate of zero while a few chose tax rates of 99 and 100 percent. In column (3) we omit the top 1 percent and bottom 5 percent of observations to limit the influence of these extreme observations. ${ }^{22}$ This restriction has only a slight impact on the size of the treatment effect. In Appendix Table 7, we show that the treatment effect is robust to a number of alternative ways of dealing with outliers, including estimates based on median regressions, winsorizing instead of dropping outliers, dropping only zero tax rates, and dropping regressive $(<21$ percent) tax rates. In all specifications, the treatment effect's magnitudes are comparable to the figures presented in Table 9. In column (4) we include controls, which has essentially no impact on the treatment effect.

While we tried to hold everything constant in the treatment and control arms except the strength of the reference point, it is possible respondents read other differences into the stories. We suspect that the most likely biases push against finding our result. In the fiveyear (treatment) scenario, the protagonist would have had a greater capacity to accumulate wealth and thus could cover the costs of a greater tax burden more easily than the protagonist who only just received the raise (control scenario). Moreover, we suspect respondents might think it unfair that, purely due to luck, in the five-year scenario the protagonists enjoys the large raise after having barely worked for the company, whereas in the one-year scenario he put in his time before getting the big raise. Given the greater willingness to redistribute gains due to luck both in our $\$ 5 / \$ 15$ experiment as well as in work cited earlier, respondents should choose a higher tax rate for the protagonist in the control scenario.

However, a concern that pushes in the opposite direction in the takeover vignette is that individuals confronted with the five-year scenario may credit the protagonist with greater merit because he has worked at the larger corporation for longer. While we emphasized that in both cases the individual would receive a raise even though he would be doing the same $j o b$ as before, in the five-year scenario the individual has apparently managed to fit in at the larger corporation, at least to the point that he has kept his (high-paying) job for half

\footnotetext{
${ }^{22}$ Another reason to exclude zero in particular is that it is the default position of the slider and thus many of these individuals may have been simply skipping through the survey.
} 
a decade. In the one-year scenario, the future performance of the protagonist at the new corporation is left unclear.

For this reason, it is useful to examine the estimates from the takeover and lottery vignettes separately, as only in the former case would the merit argument apply. Column (5) shows estimates from the takeover vignette and column (6) the lottery vignette. While the treatment effect for the takeover vignette is larger, both are negative and are statistically indistinguishable from one another.

In the final two columns, we test whether the treatment moves respondents' views about upper-income tax rates more generally. Treatment respondents are seven percentage points (roughly ten percent) less likely to support a tax hike on individuals making $\$ 250,000$ or more, though significant only at the ten-percent level. This result suggests that the vignette's framing is sufficiently salient to affect respondents' views on preferred tax rates for all highincome individuals, not just the one portrayed in the vignette. Of course, this outcome may be primed by the answer to the slider question (which always precedes it), so should be interpreted with caution.

\subsection{Discussion}

The results from the survey experiment show that individuals appear to reward more deeply embedded references points (i.e., income levels that have been experienced for longer periods of time) with lower tax rates. The magnitude of this effect is quite large. For example, Obama supporters choose a tax rate 2.96 percentage points greater than do other respondents (not shown), suggesting that our reference-point effect is over half as large as an "Obama effect." 23

While the survey experiments have documented that the strength of an individual's reference point reduces the tax rates assigned by our subjects, the precise mechanism is unclear. A literal application of consumption commitments cannot account for the results of the $\$ 5 / \$ 15$ experiment (as the money had not yet been spent and the stakes were modest). However, respondents could well be responding to the perceived consumption commitments of the protagonists in the vignettes, in the spirit of Chetty and Szeidl (2007). It is plausible that the person who became rich five years earlier would since have taken on a hefty mortgage and enrolled her children in private schools. This consumption commitments view presents a possible foundation for the existence of a loss aversion heuristic, whether for oneself or,

\footnotetext{
${ }^{23}$ To estimate this effect, we use our preferred specification from Table 9 (i.e., column 3) but substitute a "Supported Obama" indicator for the treatment indicator. The mean tax rate chosen among the control group (i.e., those who did not support Obama) is 26.1 percent. When we instead repeat this analysis with the binary "support a general upper-income tax hike" variable as our outcome, our treatment effect is $29 \%$ of the corresponding "Obama" effect.
} 
as is the case in our experiment, on behalf of others. In this paper we aim to document how asymmetric responses to gains and losses affect redistributive preference more generally and upper-income tax policy in particular, rather than attempting to distinguish amongst underlying explanations for this behavior.

It is also interesting to note that, at least along some policy dimensions, there appears to be respect for reference points in the distribution of transfer policies as well. For example, a policy that has gained popularity during the Great Recession would require welfare and food stamp recipients to pass drug tests. In a 2011 Rasumussen poll, while $53 \%$ of respondents supported mandatory drug test for new applicants to welfare, only $29 \%$ supported that same requirement for current recipients. ${ }^{24}$ As such, respondents seemed to view individuals' current benefits as more of an entitlement. The fact that many cuts in benefits are "grandfathered in" can also be viewed as an implicit respect for beneficiaries' reference points.

\section{Conclusion}

Past work has established that in many contexts, individuals display reference-dependent preferences. We provide robust evidence that, in a laboratory setting, individuals who are given the opportunity to redistribute between two recipients with unequal endowments are highly sensitive to the recipients' reference points. When the recipients do not know their initial endowments, the redistributor erases close to the full ex-ante income gap. However, redistribution is reduced by nearly twenty percent when the recipients do know their ex ante endowments. This reference-point effect is large in magnitude, more than one-half of the effect of having endowments determined via performance on an academic test versus a coin flip. Moreover, it is strongest among respondents who themselves appear the most loss-averse, at least as measured by the willingness to bear risk in the loss domain.

These findings have implications for models of optimal taxation. If losses - even for the wealthy - loom larger than gains, part of the welfare gain from redistribution may be erased. If individuals project their own loss-aversion onto others when forming their redistributive preferences, then loss-aversion might help explain the gap between voters' stated policy preferences and the more egalitarian normative prescriptions of optimal tax models or the positive predictions from standard political economy models.

Future work might examine the extent to which preference anomalies exist in decisions with direct consequences for others' (rather than one's own) payoffs in contexts other than redistribution. The limited work we have found on this question suggests that context may

\footnotetext{
${ }^{24}$ See http://stopthedrugwar.org/chronicle/2011/jul/22/national_poll_finds_ support_welf for a discussion of these results.
} 
be important, as Marshall et al. (1986) do not find, as we do, that individuals project lossaversion when they act as advisors on others' behalf. Beyond voters and advisors, there are many other roles that entail making decisions with consequences for others, such as parents, employers, and physicians.

In this paper, we have not confronted the normative issue of whether preference anomalies such as loss aversion should be respected by the social planner. Suppose that individuals behave as if their own utility is reference-dependent and that, as our work shows, they take others' loss-aversion into account when acting as social planners. Should policy-makers and economists nonetheless still restrict themselves to classical utility and social welfare functions when conducting welfare analysis? Such questions have recently been taken up in Lockwood and Weinzierl (2014).

The existence of reference-dependent preferences in redistributive decisions may also help to explain some puzzling aspects of tax policy. For example, if wealth is a more salient reference point than income, it could help to explain the lack of broad-based support for wealth taxes (and may be reason for skepticism that recent wealth tax proposals will get much traction). Our findings may suggest that tax increases - whether based on wealth or income - might be better-received if policymakers can commit to them several years in advance of their implementation, thus allowing individuals to adjust their reference wealth or income ahead of the actual change. A fuller analysis of the consequences of referencedependent utility for taxation - how reference points are set and evolve in response to policy changes or pronouncements; whether there are circumstances that attenuate or intensify the role of reference-dependence in redistributive preferences; and so forth - is a further area for future research. 


\section{References}

Abdellaoui, M., Bleichrodt, H. and Paraschiv, C. (2007). Loss aversion under prospect theory: A parameter-free measurement. Management Science, 53 (10), 16591674.

Alesina, A. and Angeletos, G.-M. (2005). Fairness and redistribution. American Economic Review, pp. 960-980.

— and PASSARELli, F. (2014). Loss aversion and politics.

Allcott, H., Mullainathan, S. and Taubinsky, D. (2014). Energy policy with externalities and internalities. Journal of Public Economics.

Ariely, D. and Norton, M. I. (2011). Building a better americaone wealth quintile at a time. Perspectives on Psychological Science, 6 (1), 9-12.

Battigalli, P., Charness, G. and Dufwenberg, M. (2013). Deception: The role of guilt. Journal of Economic Behavior \& Organization, 93, 227-232.

- and Dufwenberg, M. (2007). Guilt in games. The American Economic Review, pp. $170-176$.

Beggs, A. and Graddy, K. (2009). Anchoring effects: Evidence from art auctions. The American Economic Review, pp. 1027-1039.

Benabou, R. and OK, E. (2001). Social mobility and the demand for redistribution: The POUM hypothesis. Quarterly Journal of Economics, 116 (2), 447-487.

Bernheim, B. D. and Rangel, A. (2004). Addiction and cue-triggered decision processes. The American Economic Review, 94 (5), 1558-1590.

Boskin, M. J. and Sheshinski, E. (1978). Optimal redistributive taxation when individual welfare depends upon relative income. The Quarterly Journal of Economics, pp. 589-601.

Bowman, D., Minehart, D. and Rabin, M. (1999). Loss aversion in a consumptionsavings model. Journal of Economic Behavior 85 Organization, 38 (2), 155-178.

Chetty, R. and Szeidl, A. (2007). Consumption commitments and risk preferences. The Quarterly Journal of Economics, 122 (2), 831-877.

Di Tella, R., Haisken-De New, J. and MacCulloch, R. (2010). Happiness adaptation to income and to status in an individual panel. Journal of Economic Behavior \& Organization, 76 (3), 834-852.

Diamond, P. and SAez, E. (2011). The case for a progressive tax: from basic research to policy recommendations. The Journal of Economic Perspectives, 25 (4), 165-190.

Durante, R., Putterman, L. and Van der Weele, J. J. (2013). Preferences for redistribution and perception of fairness: An experimental study. Forthcoming, Journal of the European Economic Association.

Ellingsen, T., Johannesson, M., Tuøtta, S. and Torsvik, G. (2010). Testing guilt aversion. Games and Economic Behavior, 68 (1), 95-107. 
Genesove, D. and Mayer, C. (2001). Loss aversion and seller behavior: Evidence from the housing market. The Quarterly Journal of Economics, 116 (4), 1233-1260.

Harms, P. and Zink, S. (2003). Limits to redistribution in a democracy: a survey. European Journal of Political Economy, 19 (4), 651-668.

Kahneman, D., Knetsch, J. L. and Thaler, R. (1986). Fairness as a constraint on profit seeking: Entitlements in the market. The American economic review, pp. 728-741.

- and Tversky, A. (1979). Prospect theory: An analysis of decision under risk. Econometrica: Journal of the Econometric Society, pp. 263-291.

Kuziemko, I., Norton, M. I., Saez, E. and Stantcheva, S. (forthcoming). How elastic are preferences for redistribution? evidence from randomized survey experiments. American Economic Review.

Lee, W. and Roemer, J. E. (2006). Racism and redistribution in the United States: A solution to the problem of American exceptionalism. Journal of Public Economics, 90 (6), 1027-1052.

Leventhal, G. S. (1980). What should be done with equity theory? Springer.

Lockwood, B. and Weinzierl, M. (2014). Positive and normative judgments implicit in us tax policy, and the costs of unequal growth and recessions. Harvard Business School BGIE Unit Working Paper, (14-119).

Mankiw, N. G., Weinzierl, M. and Yagan, D. (2009). Optimal taxation in theory and practice. The Journal of Economic Perspectives, pp. 147-174.

Marshall, J. D., Knetsch, J. L. and Sinden, J. A. (1986). Agents' evaluations and the disparity in measures of economic loss. Journal of Economic Behavior 85 Organization, 7 (2), 115-127.

Meltzer, A. and Richard, S. (1981). A rational theory of the size of government. The Journal of Political Economy, 89 (5), 914-927.

Mirrlees, J. A. (1971). An exploration in the theory of optimum income taxation. Review of Economic Studies, 38 (2), 175-208.

O’Donoghue, T. and Rabin, M. (2006). Optimal sin taxes. Journal of Public Economics, 90 (10), 1825-1849.

Oswald, A. J. (1983). Altruism, jealousy and the theory of optimal non-linear taxation. Journal of Public Economics, 20 (1), 77-87.

Roemer, J. E. (1998). Why the poor do not expropriate the rich: An old argument in new garb. Journal of Public Economics, 70 (3), 399-424.

Saez, E. and Stantcheva, S. (2013). Generalized Social Marginal Welfare Weights for Optimal Tax Theory. Working Paper 18835, National Bureau of Economic Research.

WeINZIERL, M. (2014). The promise of positive optimal taxation: normative diversity and a role for equal sacrifice. Journal of Public Economics, 118, 128-142. 
Figure 1: Redistribution with standard utility functions

(a) Utility for individual $p$

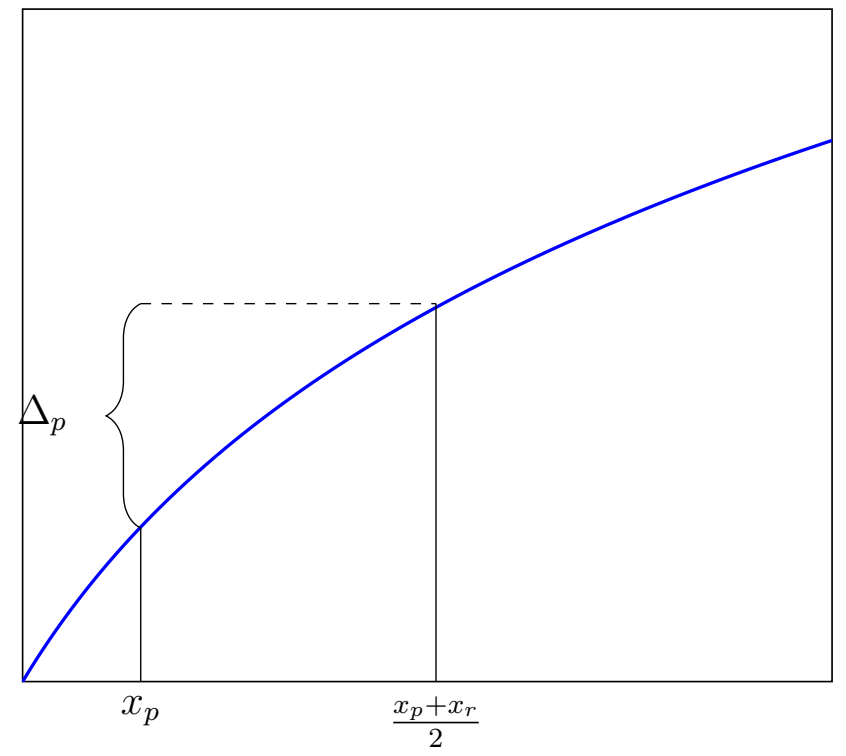

(b) Utility for individual $r$

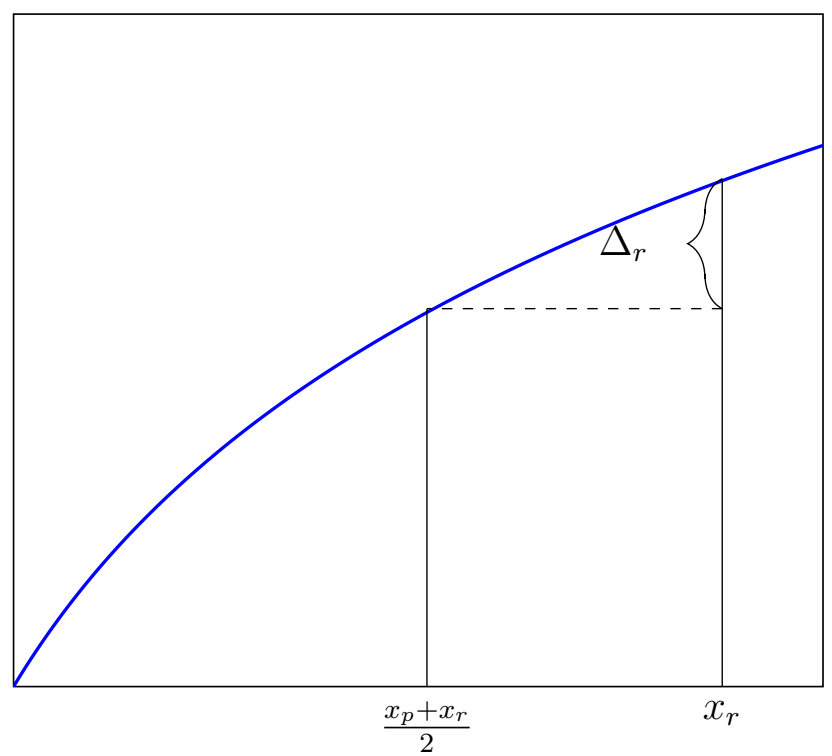

Notes: A depiction of the optimal tax solution under a utilitarian social welfare function when utility (y-axis) is a positive and strictly concave function of consumption (x-axis).

Figure 2: Redistribution with reference-dependent utility

(a) Utility for individual $p$

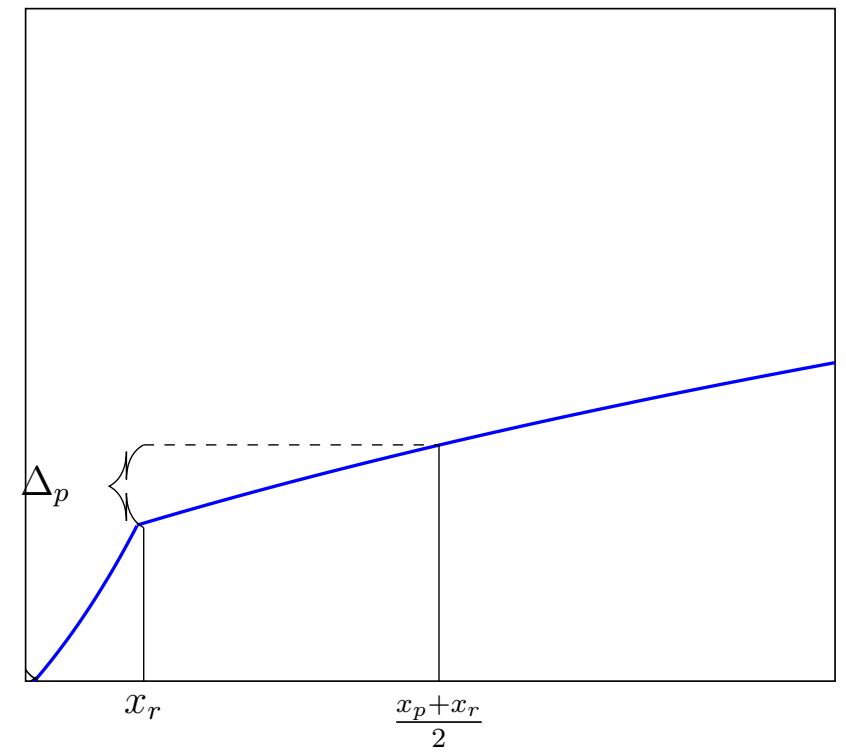

(b) Utility for individual $r$

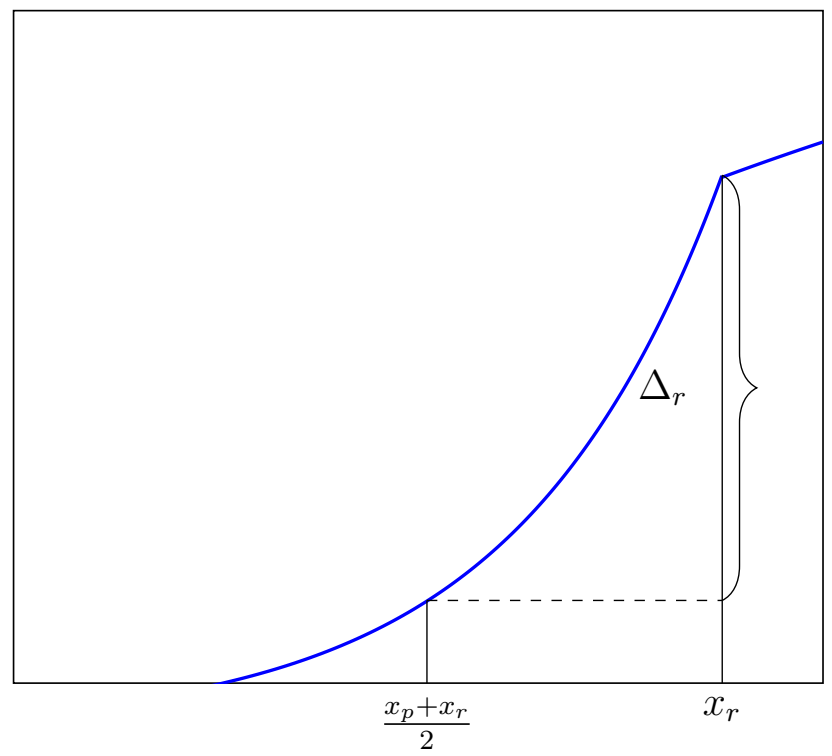

Notes: A depiction of changes in utility after full redistribution when utility functions exhibit loss-aversion. In this example, we have drawn losses from the reference point as convex and gains as concave. 
Figure 3: Treatment effects and ninety-five-percent confidence intervals for the referencepoint experiment, by session

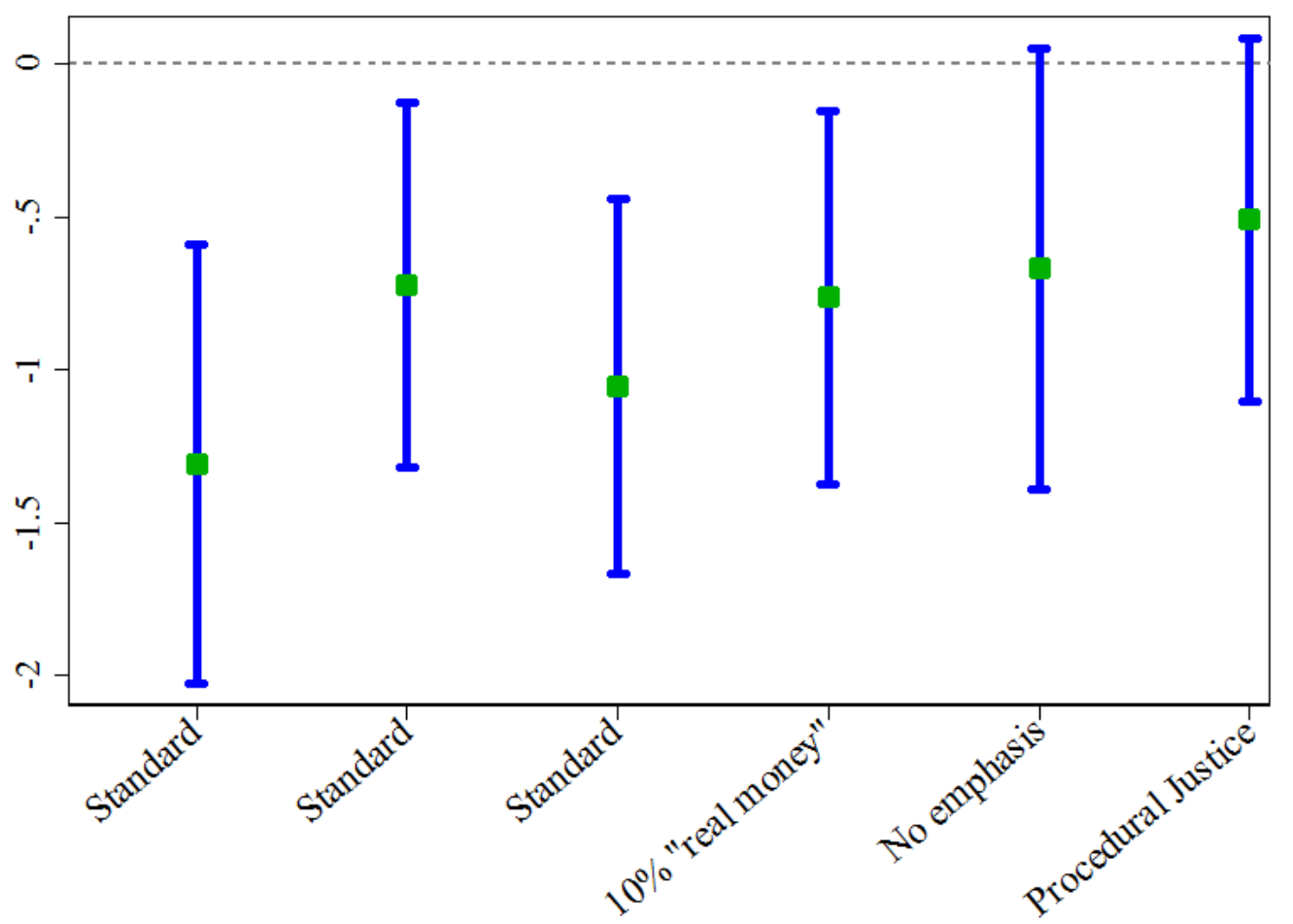

Notes: We show separately for each session the between-subject treatment effects for all rounds in which the reference-point money-transfer experiment appears first (the sample in col. 3 of Table 4). As noted in the text, there are a total of seven sessions where the money-transfer experiment appears first, but one (session six) contrasts endowments gained by luck versus merit instead of references points. Those results are reported in Table 7 but are not plotted here. 
Figure 4: Histogram of ex-post allocations for the ex-ante poorer player

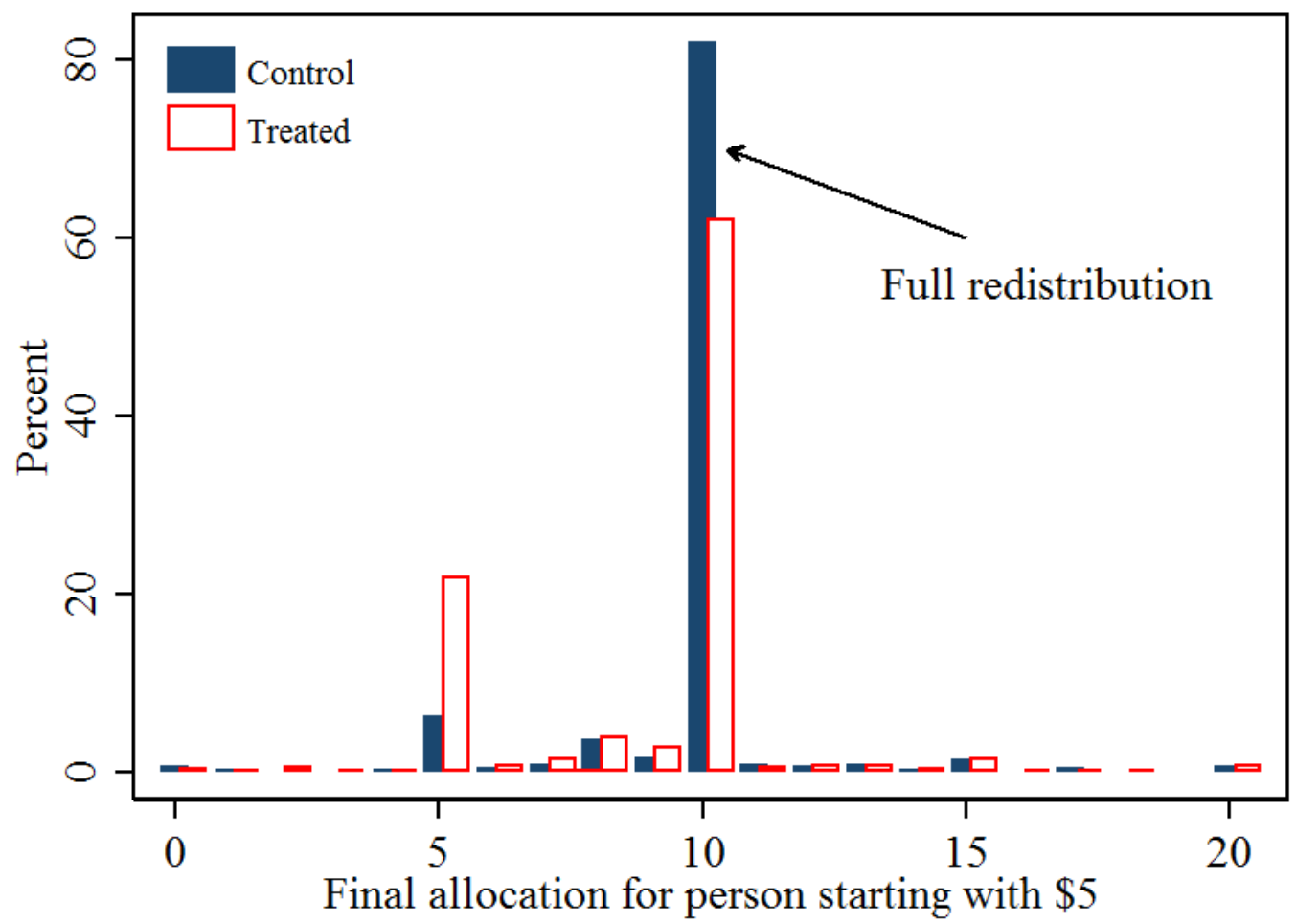

Notes: Sample used in the figure is that in our "preferred" analysis sample (Column 3, Table 4). 
Table 1: Basic summary statistics in mTurk sample compared to ACS

\begin{tabular}{lcc}
\hline & $(1)$ & $(2)$ \\
& mTurk Sample & ACS sample \\
\hline Age & 33.04 & 46.40 \\
Female & 0.444 & 0.515 \\
White & 0.773 & 0.669 \\
Black & 0.0730 & 0.120 \\
Hispanic & 0.0563 & 0.143 \\
Asian & 0.0764 & 0.0503 \\
College & 0.449 & 0.257 \\
Income $(\$ 1,000)$ & 49.47 & 71.32 \\
\hline Obervations & 2,041 & $2,369,395$ \\
\hline
\end{tabular}

Notes: Observation totals are the shared non-missing observations across all variables. Col. 1 includes all ten sessions of the experiment. Col. 2 includes all adults in the 2010 American Community Survey (weighted with the provided individual-level weights). "Income" refers to household income (in units of $\$ 1,000$ ).

Table 2: Full summary statistics in mTurk sample

\begin{tabular}{lccc}
\hline & & & \\
& Mean & Std. Dev. & $\mathrm{N}$ \\
\hline Age & 33.04 & 11.09 & 2041 \\
Female & 0.44 & 0.50 & 2041 \\
White & 0.77 & 0.42 & 2041 \\
Black & 0.07 & 0.26 & 2041 \\
Hisp & 0.06 & 0.23 & 2041 \\
Asian & 0.08 & 0.27 & 2041 \\
Income (\$1,000) & 49.47 & 39.33 & 2040 \\
Fulltime & 0.43 & 0.49 & 2041 \\
Partime & 0.14 & 0.35 & 2041 \\
College & 0.45 & 0.50 & 2041 \\
Student & 0.11 & 0.32 & 2041 \\
Supported Obama in 2012 & 0.64 & 0.48 & 2040 \\
R-loving (losses) & 1.44 & 1.06 & 1534 \\
R-loving (gains) & 0.82 & 0.91 & 1572 \\
$\Delta$ Wage unfairness for current v. new worker (cont) & 1.41 & 1.02 & 1858 \\
Higher WTA if bought house at $\$ 300 K$ (binary) & 0.79 & 0.41 & 1582 \\
\hline Notes: Sce Secion 3.2 for a dald derpen
\end{tabular}

Notes: See Section 3.2 for a detailed description of the loss-aversion variables (the last four variables in the Table). Briefly, "R-loving (losses)" takes integer values from [0,3], increasing in the number of times you choose the lottery option over the risk free option over options involving losses. "R-loving (gains)" is defined analogously, but over gains. " $\Delta$ wage unfairness" is increasing in how much more unfair a respondent deems a wage cut to a current versus a new employee.

"Higher WTA" refers to measures of anchoring bias to the original sales price of a house. 
Table 3: Further summary statistics and experimental balance

\begin{tabular}{lcccc}
\hline & $(1)$ & $(2)$ & $(3)$ & $(4)$ \\
& Cont. mean & Tr. mean & Diff. & P-val \\
\hline Age & 33.26 & 32.94 & 0.326 & 0.513 \\
Female & 0.446 & 0.436 & 0.0105 & 0.637 \\
White & 0.779 & 0.769 & 0.00952 & 0.611 \\
Black & 0.0692 & 0.0790 & -0.00977 & 0.404 \\
Hisp & 0.0536 & 0.0574 & -0.00383 & 0.709 \\
Asian & 0.0770 & 0.0738 & 0.00315 & 0.790 \\
Income $\$ 1,000)$ & 49.11 & 49.18 & -0.0756 & 0.965 \\
Fulltime & 0.430 & 0.429 & 0.00111 & 0.960 \\
Partime & 0.149 & 0.129 & 0.0199 & 0.199 \\
College & 0.447 & 0.447 & 0.000189 & 0.993 \\
Student & 0.102 & 0.121 & -0.0187 & 0.184 \\
Supported Obama in 2012 & 0.643 & 0.636 & 0.00775 & 0.718 \\
R-loving (losses) & 1.458 & 1.428 & 0.0303 & 0.582 \\
R-loving (gains) & 0.802 & 0.846 & -0.0438 & 0.349 \\
$\Delta$ Wage unfairness for current v. new worker (cont) & 1.361 & 1.450 & -0.0894 & 0.0621 \\
Higher WTA if bought house at \$300K (binary) & 0.792 & 0.794 & -0.00237 & 0.908 \\
\hline Observations & 1030 & 987 & 2017 & 2017 \\
\hline
\end{tabular}

Notes: Observation totals are the shared non-missing observations across all variables. Col. (1) displays means for those randomized into the control version of the $\$ 5 / \$ 15$ money-transfer experiment (where recipients do not know their original endowment) and col. (2) displays means for the treatment version (where recipients do know their original endowment). Col. (3) subtracts col. (2) from (1) and Col. (4) is the $p$-value associated with $H_{0}: \operatorname{Diff}=0$. 
Table 4: Main between-subject results (using only first-stage observations)

\begin{tabular}{lcccccccc}
\hline & \multicolumn{7}{c}{ Dept. var: Amount redistributed } \\
\cline { 2 - 9 } & $(1)$ & $(2)$ & $(3)$ & $(4)$ & $(5)$ & $(6)$ & $(7)$ & $(8)$ \\
\hline Treated in & $-0.797^{* * *}$ & $-0.827^{* * *}$ & $-0.829^{* * *}$ & $-0.923^{* * *}$ & $-0.824^{* * *}$ & $-0.763^{* *}$ & $-0.669^{*}$ & $-0.509^{*}$ \\
first stage & {$[0.104]$} & {$[0.106]$} & {$[0.134]$} & {$[0.103]$} & {$[0.134]$} & {$[0.312]$} & {$[0.369]$} & {$[0.304]$} \\
\hline Cont. gp. mean & 4.553 & 4.585 & 4.682 & 4.542 & 4.683 & 4.451 & 4.787 & 4.625 \\
Controls & No & No & No & No & Yes & No & No & No \\
Ex. short duration & No & Yes & Yes & Yes & Yes & Yes & Yes & Yes \\
Ex. presented second & No & No & Yes & Yes & Yes & Yes & Yes & Yes \\
Ex. incr. ineq & No & No & No & Yes & No & No & No & No \\
Ex. hypothetical & No & No & No & No & No & Yes & No & No \\
Ex. emphasis & No & No & No & No & No & No & Yes & Yes \\
Ex. promised payment & No & No & No & No & No & No & No & Yes \\
Observations & 2044 & 1903 & 1227 & 1151 & 1220 & 195 & 183 & 191 \\
\hline
\end{tabular}

Notes: All regressions include session fixed effects. Controls: age, female, white, black, Hispanic, asian, income, student status, full-time status, part-time status, Obama support, and college degree. Ex. short duration: exclude subjects who finish the survey in a suspiciously short amount of time. Ex. presented second: exclude survey sessions where the main redistribution experiment was not presented first. Ex. incr. ineq: exclude subjects who choose to make inequality-increasing reallocations. Ex. hypothetical: exclude survey sessions where the redistribution experiment was entirely hypothetical. Ex. emphasis: exclude survey sessions where the instructions to the redistribution experiment included underlined and italicized text and a reminder to the right of the person A and B bar chart. Ex. promised payment: include only the survey session where the instructions to the treatment arm of the redistribution experiment specify that the two other mTurk participants have been told the amount they initially received might increase or decrease. ${ }^{*} p<0.1,{ }^{* *} p<0.05,{ }^{* * *} p<0.01$.

Table 5: Between-subject results (extensive margin)

\begin{tabular}{lcccc}
\hline & \multicolumn{4}{c}{ Dep. v.: Complete redistribution } \\
\cline { 2 - 5 } & $(1)$ & $(2)$ & $(3)$ & $(4)$ \\
\hline Treated in first & $-0.199^{* * *}$ & $-0.203^{* * *}$ & $-0.203^{* * *}$ & $-0.211^{* * *}$ \\
stage & {$[0.0250]$} & {$[0.0241]$} & {$[0.0241]$} & {$[0.0627]$} \\
\hline Cont. gp. mean & 0.820 & 0.869 & 0.870 & 0.824 \\
Controls & No & No & Yes & No \\
Ex. odd choices & No & Yes & Yes & No \\
Ex. hypothetical & No & No & No & Yes \\
Observations & 1227 & 1151 & 1144 & 195 \\
\hline
\end{tabular}

Notes: All regressions include session fixed effects. Both subjects who finished the survey very quickly and subjects not presented the distribution experiment first were excluded from these regressions. ${ }^{*} p<0.1,{ }^{* *} p<0.05,{ }^{* * *} p<0.01$ 
Table 6: Within-subject results

\begin{tabular}{lcccccc}
\hline & \multicolumn{6}{c}{ Dept. var: Amount redistributed } \\
\cline { 2 - 7 } & $(1)$ & $(2)$ & $(3)$ & $(4)$ & $(5)$ & $(6)$ \\
\hline Treatment & $-0.762^{* * *}$ & $-0.703^{* * *}$ & $-0.812^{* * *}$ & $-0.646^{* * *}$ & $-0.727^{* * *}$ & $-0.309^{*}$ \\
stage & {$[0.0803]$} & {$[0.126]$} & {$[0.103]$} & {$[0.193]$} & {$[0.235]$} & {$[0.181]$} \\
\hline Cont. gp. mean & 4.665 & 4.646 & 4.682 & 4.364 & 4.973 & 4.586 \\
Sample & All & T $\rightarrow \mathrm{C}$ & $\mathrm{C} \rightarrow \mathrm{T}$ & All & All & All \\
Ex. hypothetical & No & No & No & Yes & No & No \\
Ex. emphasis & No & No & No & No & Yes & No \\
Ex. promised payment & No & No & No & No & No & Yes \\
Observations & 2373 & 1131 & 1242 & 390 & 366 & 382 \\
\hline
\end{tabular}

Notes: All regressions include respondent fixed effects. Subjects who finished the survey very quickly and were not presented the distribution experiment first were excluded. $C \rightarrow T$ denotes the subsample that was first randomized into the control scenario and then the treatment scenario. $T \rightarrow C$ denotes the subsample that was first randomized into the treatment scenario and then the control scenario. ${ }^{*} p<0.1,{ }^{* *} p<0.05,{ }^{* * *} p<0.01$

Table 7: Luck (control) versus merit (treatment), between-subject results

\begin{tabular}{lccccc}
\hline & \multicolumn{2}{c}{ Dep. v.: Amount redistributed } & & \multicolumn{2}{c}{ Dep. v.: Complete redistribution } \\
\cline { 2 - 3 } \cline { 6 - 6 } & $(1)$ & $(2)$ & & $(3)$ & $(4)$ \\
\hline Treated in first & $-1.806^{* * *}$ & $-1.641^{* * *}$ & & $-0.301^{* * *}$ & $-0.257^{* * *}$ \\
stage & {$[0.360]$} & {$[0.368]$} & & {$[0.0664]$} & {$[0.0682]$} \\
\hline Cont. gp. mean & 4.515 & 4.510 & & 0.699 & 0.696 \\
Controls & No & Yes & & No & Yes \\
Observations & 206 & 205 & & 206 & 205 \\
\hline
\end{tabular}

Notes: All regressions include session fixed effects. Subjects who finished the survey very quickly or were not presented the distribution experiment first were excluded from these regressions.

${ }^{*} p<0.1,{ }^{* *} p<0.05,{ }^{* * *} p<0.01$ 
Table 8: Interacting loss-aversion measures with treatment status

\begin{tabular}{|c|c|c|c|c|c|c|c|c|}
\hline & \multicolumn{8}{|c|}{ Dept. var: Amount redistributed } \\
\hline & (1) & $(2)$ & (3) & (4) & (5) & (6) & (7) & (8) \\
\hline $\begin{array}{l}\text { Treated in first } \\
\text { stage }\end{array}$ & $\begin{array}{c}-0.829^{* * *} \\
{[0.134]}\end{array}$ & $\begin{array}{l}-0.130 \\
{[0.278]}\end{array}$ & $\begin{array}{c}-0.712^{* * *} \\
{[0.223]}\end{array}$ & $\begin{array}{c}-0.526^{* * *} \\
{[0.177]}\end{array}$ & $\begin{array}{c}-1.009^{* * *} \\
{[0.355]}\end{array}$ & $\begin{array}{c}-1.070^{* * *} \\
{[0.248]}\end{array}$ & $\begin{array}{l}-0.171 \\
{[0.588]}\end{array}$ & $\begin{array}{l}-0.691 \\
{[0.550]}\end{array}$ \\
\hline $\begin{array}{l}\text { Tr. x R-loving } \\
\text { (losses) }\end{array}$ & & $\begin{array}{r}-0.395^{* *} \\
{[0.156]}\end{array}$ & & & & & $\begin{array}{c}-0.403^{* *} \\
{[0.157]}\end{array}$ & \\
\hline $\begin{array}{l}\text { Tr. x R-loving } \\
\text { (gains) }\end{array}$ & & & $\begin{array}{l}0.0364 \\
{[0.181]}\end{array}$ & & & & & \\
\hline Tr. x R-loving (L-G) & & & & $\begin{array}{c}-0.237^{* *} \\
{[0.114]}\end{array}$ & & & & $\begin{array}{c}-0.242^{* *} \\
{[0.115]}\end{array}$ \\
\hline Tr. x Higher WTA & & & & & $\begin{array}{c}0.475 \\
{[0.400]}\end{array}$ & & & \\
\hline $\begin{array}{l}\text { Tr. x } \Delta \text { Wage } \\
\text { unfairness }\end{array}$ & & & & & & $\begin{array}{c}0.221 \\
{[0.140]}\end{array}$ & & \\
\hline Cont. gp. mean & 4.682 & 4.671 & 4.649 & 4.641 & 4.671 & 4.695 & 4.670 & 4.640 \\
\hline Incl. Covar x Treat & No & No & No & No & No & No & Yes & Yes \\
\hline Observations & 1227 & 791 & 811 & 781 & 812 & 1055 & 788 & 778 \\
\hline
\end{tabular}

Notes: All regressions include session fixed effects. "Tr. x R-loving (losses)", "Tr. x R-loving (gains)", and "Tr. x R-loving (L-G)" refer to the interaction of the the risk-loving over losses, risk-loving over gains, and risk-loving over losses relative to that over gains variables with Treat. "Tr. x Higher WTA" refers to the interaction of the variable that indicates that the respondent demanded a higher house price with a $\$ 300,000$ initial price than the $\$ 250,000$ price and Treat. "Tr. $\Delta$ Wage unfairness" refers to the interaction of the difference between the fairness ratings of the cut to the wages of the current and new coffee shop employees and Treat. "Inc. Covar $\mathrm{x}$ Treat" means that interactions with Treat and the following list of variables are all included simultaneously: age, female, white, income, student status, full-time status, Obama support, and college degree. The main effects of these interactions are controlled for as well in columns 7 and 8 . ${ }^{*} p<0.1,{ }^{* *} p<0.05,{ }^{* * *} p<0.01$ 
Table 9: Preferred tax for person who became rich five versus one year ago

\begin{tabular}{|c|c|c|c|c|c|c|c|c|}
\hline & \multicolumn{6}{|c|}{ Dept. var: Chosen tax rate } & \multicolumn{2}{|c|}{ Dept. var: Favor tax hike } \\
\hline & (1) & $(2)$ & (3) & (4) & $(5)$ & (6) & (7) & (8) \\
\hline $\begin{array}{l}\text { Treated (rich for } \\
\text { five yrs.) }\end{array}$ & $\begin{array}{l}-0.0117^{*} \\
{[0.00644]} \\
\end{array}$ & $\begin{array}{l}-0.0171^{* *} \\
{[0.00751]} \\
\end{array}$ & $\begin{array}{c}-0.0168^{* * *} \\
{[0.00630]} \\
\end{array}$ & $\begin{array}{c}-0.0168^{* * *} \\
{[0.00631]} \\
\end{array}$ & $\begin{array}{c}-0.0185^{* * *} \\
{[0.00709]} \\
\end{array}$ & $\begin{array}{l}-0.0120 \\
{[0.0134]} \\
\end{array}$ & $\begin{array}{l}-0.0735^{*} \\
{[0.0415]} \\
\end{array}$ & $\begin{array}{l}-0.0728^{*} \\
{[0.0407]} \\
\end{array}$ \\
\hline Cont. gp. mean & 0.288 & 0.286 & 0.288 & 0.288 & 0.290 & 0.284 & 0.777 & 0.777 \\
\hline Ex. if presented second & No & Yes & Yes & Yes & Yes & Yes & Yes & Yes \\
\hline Adj. for outliers? & No & No & Yes & Yes & Yes & Yes & n.a. & n.a. \\
\hline Controls & No & No & No & Yes & No & No & No & Yes \\
\hline Vignette & Both & Both & Both & Both & Takeover & Lottery & Both & Both \\
\hline Observations & 1097 & 721 & 694 & 682 & 513 & 181 & 446 & 438 \\
\hline
\end{tabular}

Notes: All regressions include session fixed effects. Subjects who finished the survey very quickly are excluded from the regression. "Adj. for outliers" indicates that the lowest five percent and the highest one percent of chosen tax rates are dropped (the asymmetry is due to a small mass of zeros, the default position of the slider). "Vignette" refers to the brief description of the event that led to the sudden increase in earnings. "Controls" refer to those specified in Table $4 .{ }^{*} p<0.1,{ }^{* *} p<0.05,{ }^{* * *} p<0.01$ 
Appendix Figure 1: Main redistribution experiment (control arm)

Consider two other participants on mTurk, person A and person B. Based on a coin flip, we have given $\$ 5$ to person $A$ and $\$ 15$ to person B.

You can now transfer money between persons $A$ and $B$. Persons $A$ and $B$ are not told how much money they were initially given. If you decide to give Person A $\$ X$ instead of $\$ 5$, they will simply be told that they have been given $\$ X$, and will not know how much they started with. Nor will they know that there is another person (Person B) involved, or that a third party (you) determined the money they received.

Please indicate below what transfer, if any, you would make.

-Transfer more to Person A
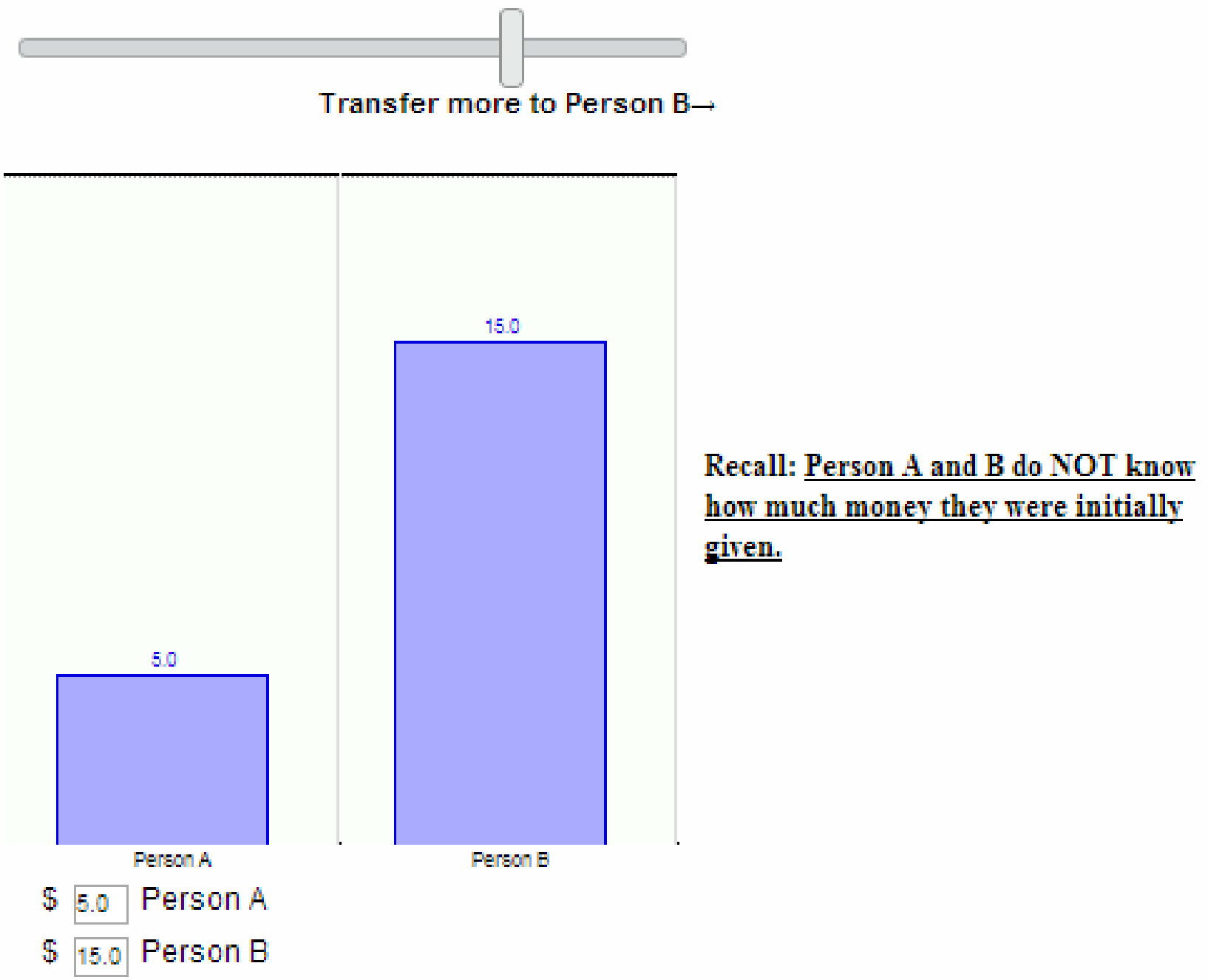
Appendix Figure 2: Main redistribution experiment (treatment arm)

Consider two other participants on mTurk, person A and person B. Based on a coin flip, we have given $\$ 5$ to person $A$ and $\$ 15$ to person $B$.

You can now transfer money between persons $A$ and $B$. Persons $A$ and $B$ have already been told how much money we have given them. If you decide to give Person A \$X instead of $\$ 5$, they will be told that they now have $\$ X$ instead of $\$ 5$. They will not know that there is another person (Person B) involved, or that a third party (you) determined the money they received.

Please indicate below what transfer, if any, you would make.

-Transfer more to Person A

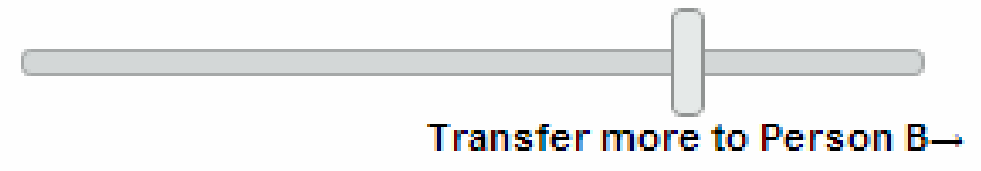

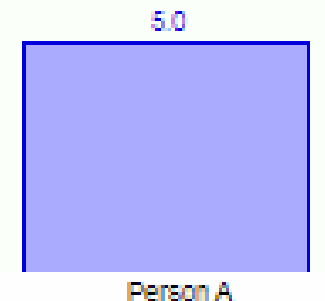

$\$ 5.0$ Person A

$\$ 15.0$ Person $\mathrm{B}$
Recall: Person A and B have already been told how much money they were initially given. 
Appendix Figure 3: Income tax experiment (control arm)

There has been much talk about whether wealthy families are paying their fair share in taxes.

Consider the following person. He has been working for about five years as a regional sales manager at a medium-sized firm. This year, his firm was taken over by a larger corporation. While he will be doing the same job as before, to make his pay compatible with the earnings of employees in his position at the larger firm, his salary is now doubled, to $\$ 250,000$.

If it were up to you, how much of his salary should he pay in taxes? (As a basis of comparison, the average American pays about 22 percent in taxes on the income they make.)

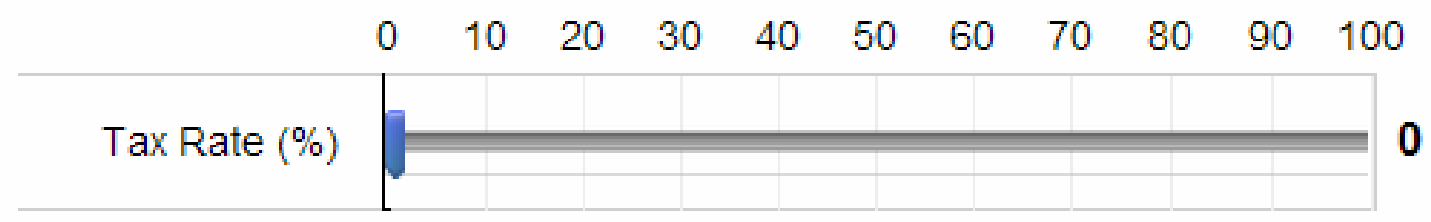

Appendix Figure 4: Income tax experiment (treatment arm)

There has been much talk about whether wealthy families are paying their fair share in taxes.

Consider the following person. He started five years ago as a regional sales manager at a medium-sized firm. Soon after starting, his firm was taken over by a larger corporation. While he did the same job as before, his salary was doubled to make his pay compatible with the earnings of employees in his position at the larger firm. Since then, his annual salary has been roughly steady and is now $\$ 250,000$.

If it were up to you, how much of his salary should he pay in taxes? (As a basis of comparison, the average American pays about 22 percent in taxes on the income they make.)

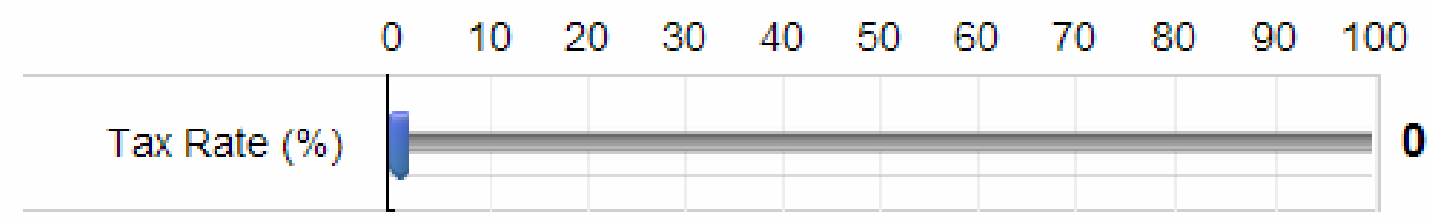


Appendix Figure 5: Histogram of ex-post allocations for the ex-ante poorer player, luck (control) versus merit (treatment) session

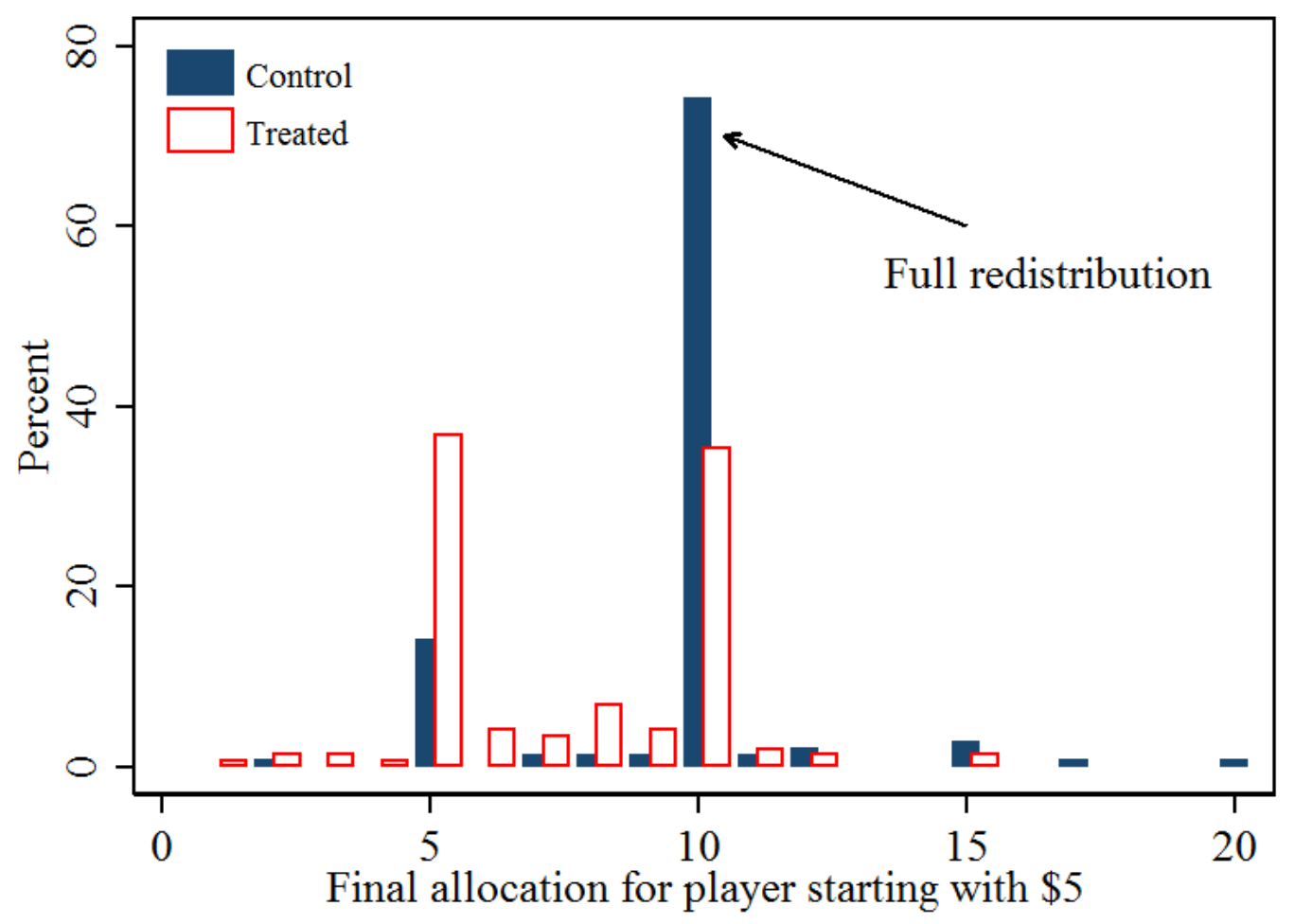


Appendix Table 1: Survey Session Details

\begin{tabular}{lcccccc}
\hline Session & Date & Survey Obs & Analysis Obs & First Exper. & $\$ 5 / \$ 15$ version & $\$ 250,000$ Tax $Q$ \\
\hline One & Feb 13, 2014 & 187 & 187 & $\$ 5 / \$ 15$ & Standard & No \\
Two & Feb 27, 2014 & 312 & 295 & $\$ 5 / \$ 15$ & Standard & No \\
Three & Mar 10, 2014 & 301 & 250 & $\$ 5 / \$ 15$ & Standard & No \\
Four & Mar 21, 2014 & 352 & 282 & Tax & Standard & Yes \\
Five & Mar 24, 2014 & 374 & 303 & Tax & Standard & Yes \\
Six & Apr 25, 2014 & 321 & 228 & $\$ 5 / \$ 15$ & Standard & No \\
Seven & May 28, 2014 & 312 & 207 & $\$ 5 / \$ 15$ & Standard & Yes \\
Eight & May 30, 2014 & 332 & 216 & $\$ 5 / \$ 15$ & Real Money & Yes \\
Nine & Jun 19, 2014 & 314 & 200 & Tax & No Emphasis & Yes \\
Ten & Dec 11, 2014 & 307 & 196 & $\$ 5 / \$ 15$ & No Promises & No
\end{tabular}

Notes: Total observations and analysis sample observations differ because in almost all analysis we drop anyone who took a previous survey. Further details on each session can be found in the text. 
Appendix Table 2: Correlation across loss-aversion measures

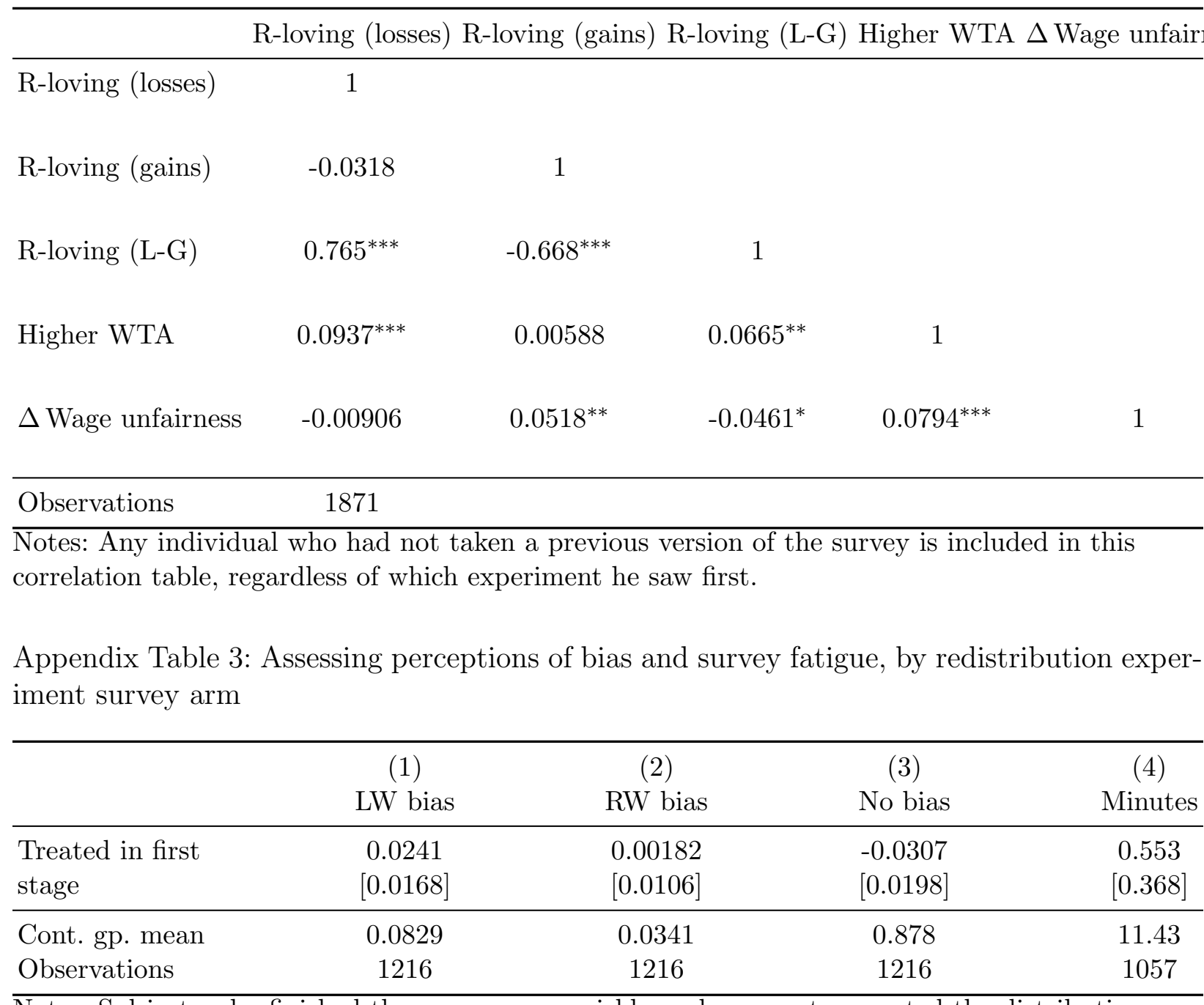

Notes: Subjects who finished the survey very quickly and were not presented the distribution experiment first were excluded from these regressions. 
Appendix Table 4: Differential treatment effects from between-subject results

\begin{tabular}{|c|c|c|c|c|c|c|c|c|c|c|c|c|}
\hline & \multicolumn{12}{|c|}{ Dept. var: Amount redistributed } \\
\hline & (1) & $(2)$ & $(3)$ & (4) & $(5)$ & (6) & (7) & $(8)$ & (9) & $(10)$ & (11) & $(12)$ \\
\hline Treated in & $-1.537^{* * *}$ & $-0.904^{* * *}$ & $-0.920^{* * *}$ & $-0.819^{* * *}$ & $-0.834^{* * *}$ & $-0.811^{* * *}$ & $-0.731^{* * *}$ & $-0.851^{* * *}$ & $-0.855^{* * *}$ & $-0.814^{* * *}$ & $-0.636^{* * *}$ & $-0.621^{* * *}$ \\
\hline first stage & [0.428] & [0.181] & [0.291] & [0.139] & [0.139] & [0.139] & {$[0.222]$} & [0.141] & {$[0.179]$} & {$[0.146]$} & {$[0.182]$} & {$[0.226]$} \\
\hline Tr. x Age & $\begin{array}{l}0.0211^{*} \\
{[0.0120]}\end{array}$ & & & & & & & & & & & \\
\hline $\operatorname{Tr} . \mathrm{x}$ & & 0.180 & & & & & & & & & & \\
\hline Female & & {$[0.271]$} & & & & & & & & & & \\
\hline Tr. $\mathrm{x}$ & & & 0.123 & & & & & & & & & \\
\hline White & & & {$[0.328]$} & & & & & & & & & \\
\hline Tr. $\mathrm{x}$ & & & & -0.0623 & & & & & & & & \\
\hline Black & & & & {$[0.544]$} & & & & & & & & \\
\hline Tr. x Hisp & & & & & $\begin{array}{c}0.158 \\
{[0.555]}\end{array}$ & & & & & & & \\
\hline $\operatorname{Tr} . \mathrm{x}$ & & & & & & -0.180 & & & & & & \\
\hline Asian & & & & & & {$[0.534]$} & & & & & & \\
\hline $\operatorname{Tr} . \mathrm{x}$ & & & & & & & -0.00000194 & & & & & \\
\hline Income & & & & & & & {$[0.00000370]$} & & & & & \\
\hline Tr. $\mathrm{x}$ & & & & & & & & 0.292 & & & & \\
\hline Student & & & & & & & & {$[0.460]$} & & & & \\
\hline $\operatorname{Tr} . \mathrm{x}$ & & & & & & & & & 0.0719 & & & \\
\hline Fulltime & & & & & & & & & {$[0.272]$} & & & \\
\hline $\operatorname{Tr} . \mathrm{x}$ & & & & & & & & & & -0.0622 & & \\
\hline Partime & & & & & & & & & & {$[0.378]$} & & \\
\hline Tr. $\mathrm{x}$ & & & & & & & & & & & -0.412 & \\
\hline College & & & & & & & & & & & {$[0.271]$} & \\
\hline $\operatorname{Tr} . \mathrm{x}$ & & & & & & & & & & & & -0.314 \\
\hline Obama & & & & & & & & & & & & {$[0.281]$} \\
\hline Cont. gp. mean & 4.683 & 4.683 & 4.683 & 4.683 & 4.683 & 4.683 & 4.683 & 4.683 & 4.683 & 4.683 & 4.683 & 4.683 \\
\hline Observations & 1220 & 1220 & 1220 & 1220 & 1220 & 1220 & 1220 & 1220 & 1220 & 1220 & 1220 & 1220 \\
\hline
\end{tabular}

Notes: All regressions include session fixed effects and the controls listed in Table 4. Subjects who finished the survey very quickly and were not presented the distribution experiment first were excluded from these regressions. ${ }^{*} p<0.1,{ }^{* *} p<0.05,{ }^{* * *} p<0.01$ 
Appendix Table 5: Interacting loss-aversion measures with treatment status (SAT v. coin toss experiment)

\begin{tabular}{|c|c|c|c|c|c|c|c|c|}
\hline & & & Dept. var: & : Amount & redistri & ibuted & & \\
\hline & (1) & (2) & (3) & (4) & (5) & (6) & (7) & $(8)$ \\
\hline $\begin{array}{l}\text { Treated in first } \\
\text { stage }\end{array}$ & $\begin{array}{c}-1.806^{* * *} \\
{[0.360]}\end{array}$ & $\begin{array}{c}-1.963^{* * *} \\
{[0.612]}\end{array}$ & $\begin{array}{c}-2.135^{* * *} \\
{[0.479]}\end{array}$ & $\begin{array}{c}-1.695^{* * *} \\
{[0.400]}\end{array}$ & $\begin{array}{l}-1.230 \\
{[0.819]}\end{array}$ & $\begin{array}{c}-2.155^{* * *} \\
{[0.673]}\end{array}$ & $\begin{array}{l}-1.848 \\
{[1.252]}\end{array}$ & $\begin{array}{l}-1.760 \\
{[1.223]}\end{array}$ \\
\hline $\begin{array}{l}\text { Tr. x R-loving } \\
\text { (losses) }\end{array}$ & & $\begin{array}{l}0.0914 \\
{[0.361]}\end{array}$ & & & & & $\begin{array}{l}-0.146 \\
{[0.372]}\end{array}$ & \\
\hline $\begin{array}{l}\text { Tr. x R-loving } \\
\text { (gains) }\end{array}$ & & & $\begin{array}{c}0.438 \\
{[0.381]}\end{array}$ & & & & & \\
\hline Tr. x R-loving (L-G) & & & & $\begin{array}{l}-0.200 \\
{[0.264]}\end{array}$ & & & & $\begin{array}{l}-0.296 \\
{[0.259]}\end{array}$ \\
\hline Tr. x Higher WTA & & & & & $\begin{array}{l}-0.758 \\
{[0.913]}\end{array}$ & & & \\
\hline $\begin{array}{l}\text { Tr. x } \Delta \text { Wage } \\
\text { unfairness }\end{array}$ & & & & & & $\begin{array}{c}0.239 \\
{[0.381]}\end{array}$ & & \\
\hline Cont. gp. mean & 4.515 & 4.545 & 4.510 & 4.541 & 4.510 & 4.515 & 4.541 & 4.515 \\
\hline Incl. Covar x Treat & No & No & No & No & No & No & Yes & Yes \\
\hline Observations & 206 & 195 & 203 & 192 & 205 & 206 & 194 & 195 \\
\hline
\end{tabular}

Notes: All regressions include session fixed effects and the controls listed in Table 4. "Tr. $\mathrm{x}$

R-loving (losses)", "Tr. x R-loving (gains)", and "Tr. x R-loving (L-G)" refer to the interaction of the the risk-loving over losses, risk-loving over gains, and risk-loving over losses relative to that over gains variables with Treat. "Tr. x Higher WTA" refers to the interaction of the variable that indicates that the respondent demanded a higher house price with a $\$ 300,000$ initial price than the $\$ 250,000$ price and Treat. "Tr. $\Delta$ Wage unfairness" refers to the interaction of the difference between the fairness ratings of the cut to the wages of the current and new coffee shop employees and Treat. "Inc. Covar x Treat" means that interactions with Treat and the following list of variables are all included simultaneously: age, female, white, income, student status, full-time status, Obama support, and college degree. ${ }^{*} p<0.1,{ }^{* *} p<0.05,{ }^{* * *} p<0.01$ 
Appendix Table 6: Main between-subject redistribution and tax results, includes subjects that participated in multiple batches

\begin{tabular}{lcccc}
\hline & \multicolumn{2}{c}{ Dept. var: Amount redistributed } & & Dept. var: Chosen tax rate \\
\cline { 2 - 3 } & $(1)$ & $(2)$ & $(3)$ \\
\hline Treated & $-0.785^{* * *}$ & -0.286 & $-0.0138^{* *}$ \\
& {$[0.119]$} & {$[0.239]$} & {$[0.00564]$} \\
Tr. x R-loving & & $-0.282^{* *}$ & \\
(losses) & & {$[0.135]$} & 0.289 \\
Cont. gp. mean & 4.595 & 4.584 & 908 \\
Observations & 1577 & 1090 & \\
\hline
\end{tabular}

Notes: The first column replicates the analysis from col. 3 of Table 4 , the second replicates the analysis from col 2. of Table 8, and the third replicates the analysis from col. 2 of Table 9 . ${ }^{*} p<0.1,{ }^{* *} p<0.05,{ }^{* * *} p<0.01$

Appendix Table 7: Replicating the main tax result with various outlier adjustments

\begin{tabular}{lccccc}
\hline & \multicolumn{5}{c}{ Dept. var: Chosen tax rate } \\
\cline { 2 - 6 } & $(1)$ & $(2)$ & $(3)$ & $(4)$ & $(5)$ \\
\hline Treated (rich for & $-0.0168^{* * *}$ & $-0.0300^{* * *}$ & $-0.0169^{* *}$ & $-0.0158^{* *}$ & $-0.0127^{* *}$ \\
five yrs.) & {$[0.00630]$} & {$[0.00883]$} & {$[0.00671]$} & {$[0.00739]$} & {$[0.00562]$} \\
\hline Cont. gp. mean & 0.288 & 0.286 & 0.286 & 0.287 & 0.306 \\
Outlier adjustment & Drop (orig. spec.) & Qreg & Winsorize & Drop 0s & Drop regr. \\
Observations & 694 & 721 & 721 & 717 & 602 \\
\hline
\end{tabular}

Notes: The first column replicates the preferred specification from Table 9 (col. 3), where outliers below the bottom fifth percent and above the higher one percentile are dropped. "Qreg" refers to median regression on the entire sample. "Winsoring" winsorizes the outliers in Col. (1) instead of dropping them. Col. (4) merely drops those who choose a zero tax rate while col. (5) drops anyone who chooses a regressive tax rate (i.e., a rate less than the average rate of 22 percent). ${ }^{*} p<0.1,{ }^{* *} p<0.05,{ }^{* * *} p<0.01$ 


\section{Details from the excluded experimental session}

In one session (April 17, 2014), instead of having individuals transfer money between the recipients using the slider, we tried to use a drop-down menu (which listed all twenty possible money transfers). In all cases, "no transfer" was listed first, which likely caused strong anchoring effects. More seriously, we only realized ex post that the drop-down menu covered up the graphic of the two recipients' endowments (which in the slider version respondents could see change in real time as they moved from one allocation to the other).

We report results from this session below but do not include them in our main results.

\begin{tabular}{lccc}
\hline & \multicolumn{3}{c}{ Dept. var: Amount redistributed } \\
\cline { 2 - 4 } & $(1)$ & $(2)$ & $(3)$ \\
\hline Treated in & -0.151 & -0.467 & -0.521 \\
first stage & {$[0.336]$} & {$[0.318]$} & {$[0.338]$} \\
\hline Cont. gp. mean & 3.747 & 3.713 & 3.699 \\
Controls & No & No & Yes \\
Ex. short duration & Yes & Yes & Yes \\
Ex. incr. ineq & No & Yes & Yes \\
Observations & 209 & 200 & 197 \\
\hline
\end{tabular}

Notes: Subjects who finished the survey very quickly were excluded.

${ }^{*} p<0.1,{ }^{* *} p<0.05,{ }^{* * *} p<0.01$ 